NIST

PUBLICATIONS

\section{Conformity Assessment Workshop on Electromagnetic Compatibility}

Bert G. Simson

U.S. DEPARTMENT OF COMMERCE National Institute of Standards and Technology

Office of Standards Services

Gaithersburg, MD 20899

U.S. DEPARTMENT OF COMMERCE Robert A. Mosbacher, Secretary NATIONAL INSTITUTE OF STANDARDS AND TECHNOLOGY

John W. Lyons, Director 



\section{Conformity Assessment Workshop on Electromagnetic Compatibility}

\section{Bert G. Simson}

U.S. DEPARTMENT OF COMMERCE National Institute of Standards and Technology Office of Standards Services Gaithersburg, MD 20899

June 1991

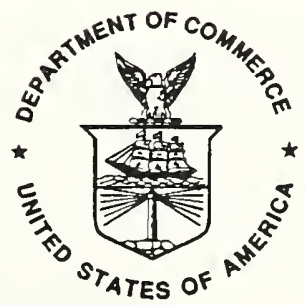

U.S. DEPARTMENT OF COMMERCE Robert A. Mosbacher, Secretary NATONAL INSTITUTE OF STANDARDS AND TECHNOLOGY

John W. Lyons, Director 



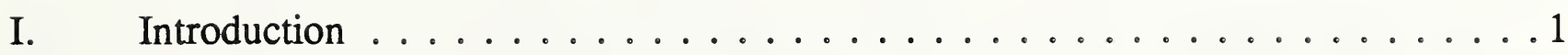

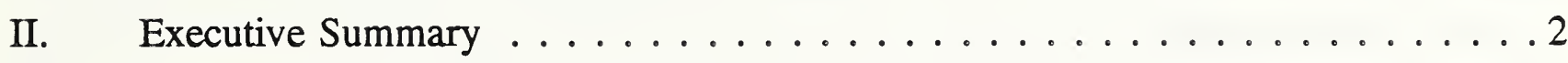

III. Background $\ldots \ldots \ldots \ldots \ldots \ldots \ldots \ldots \ldots \ldots \ldots \ldots \ldots \ldots \ldots \ldots$

IV. Panel Presentations $\ldots \ldots \ldots \ldots \ldots \ldots \ldots \ldots$

V. Responses to Questions from the Audience . . . . . . . . . . . 10

VI. Recommendations ....................... 13

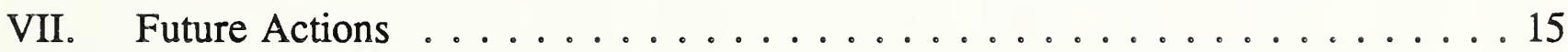

List of Appendixes

A. Panel Members and Attendees . . . . . . . . . . . . . . 17

B. Federal Register Notice . . . . . . . . . . . . . . . . . 23

C. Presentations by U.S. Government Representatives ${ }^{1}$

1. Charles Ludolph . . . . . . . . . . . . . . . . . . . . 29

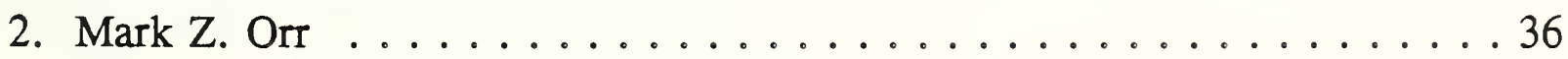

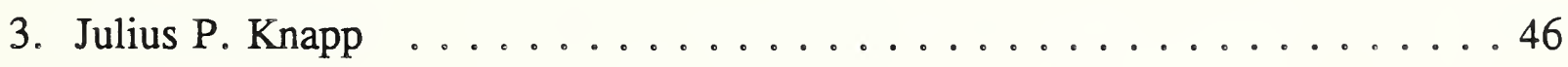

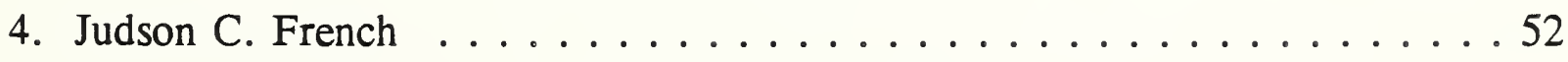

D. Presentations by Private Sector Representatives ${ }^{1}$

1. Walter A. Poggi ...................... 57

${ }^{1}$ Material in Appendixes $\mathrm{C}$ and $\mathrm{D}$ was provided by the panelists. 
2. James $\mathrm{Wm}$. Johnson . . . . . . . . . . . . . . 60

3. Glen Dash . . . . . . . . . . . . . . . . . 76

4. Keith Mowry . . . . . . . . . . . . . . . . . . . . . . . . 899

5. H. R. Hofmann . . . . . . . . . . . . . . . . . 101

6. Dr. Mirko Matejic . . . . . . . . . . . . . . . . . . . 102

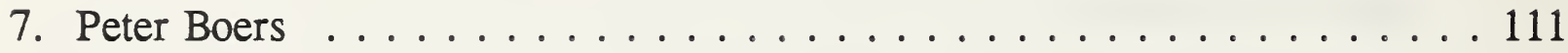




\section{Introduction}

The National Institute of Standards and Technology (NIST) is cosponsoring a series of workshops with private sector interests to identify the needs for coordination and representation of U.S. conformity assessment interests abroad. A conformity assessment workshop on electromagnetic compatibility (EMC), the second in the series, was cosponsored by the NIST, the American Council of Independent Laboratories (ACIL), and the American Electronics Association (AEA). The purpose was to determine how the U.S. Government can assist laboratories and others interested in conformity assessment for electromagnetic compatibility, to gain acceptance in international markets, such as the European Community (EC).

Recommendations developed by participating private sector panelists at this workshop had several commonalities with recommendations developed during an earlier Pressure Vessel Workshop (NISTIR 4542). Both recommended that: (1) the U.S. Government should assume an active role in representing their industries in negotiations with the EC with the goal of designating notified bodies within the United States; (2) the U.S. Government sponsor advisory committees focussed on conformity assessment issues of specific interest to them; and (3) NIST should assume a proactive role in disseminating information about draft regional and international standards for pressure vessel and EMC areas. 


\section{Executive Summary}

In an April 1990 hearing conducted by the National Institute of Standards and Technology (NIST), a panel of Government experts explored possible Government roles to serve the needs of U.S. industry in international standards development and conformity assessment. One of the conclusions in the analysis of the hearing record (NISTIR 4367) states that "The Government should sponsor or cosponsor with interested parties from the private sector a series of workshops with various industry sectors..."

The purpose of the electromagnetic compatibility (EMC) workshop, cosponsored by the American Council of Independent Laboratories (ACIL), the American Electronics Association (AEA), and the National Institute of Standards and Technology (NIST), was to explore how the U.S. Government can assist industry in conformity assessment activities aimed at gaining acceptance of EMC test results in such international markets as the European Community. The workshop was held on April 4, 1991, in the U.S. Department of Commerce building, Washington D.C.

Fifty-four persons attended the workshop, which focused on information technology equipment (ITE). A panel consisting of Government and private sector representatives heard presentations from 10 of its members.

The following recommendations were reached by consensus of the EMC workshop private sector panelists:

"1. The U.S. Government should establish an electromagnetic compatibility (EMC) sectoral advisory committee, composed of all interested parties, to assist in the development of positions for use as a basis for negotiations with the European Community (EC) on matters relating to conformity assessment.

"2. The National Voluntary Laboratory Accreditation Program (NVLAP) and the Federal Communications Commission (FCC) should harmonize existing EMC accreditation programs.

"3. The U.S. Government should negotiate an agreement with the European Commission making it possible to designate notified bodies for the EMC sector in the United States.

"4. The U.S. Government should take a formal role in accrediting conformity assessment programs as a means of satisfying European Community directives.

"5. The National Institute of Standards and Technology should take a proactive role in disseminating information to affected interests in the EMC area." 


\section{Background}

In July 1989, the Department of Commerce (DOC) conducted a two-day hearing to determine U.S. private sector interests in the European Community's standard development and conformity assessment efforts. In another hearing, held in April 1990 by the National Institute of Standards and Technology (NIST), a panel of Government experts explored possible Government roles to serve the needs of U.S. industry in international standards development and conformity assessment. Sixty-five organizations and individuals made oral presentations at the April, 1990 hearing, and 257 additional written comments were submitted for the record.

One of the conclusions in the analysis of the April hearing record (NISTIR 4367) states that "The Government should sponsor or cosponsor with interested parties from the private sector a series of workshops with various industry sectors to specify more precisely the needs for coordination and representation of U.S. conformity assessment interests abroad. Then, appropriate systems should be developed to meet those needs and promote effective application of these mechanisms in behalf of U.S. manufacturers and exporters. Particular consideration should be focussed on the division of responsibilities between Government and the private sector in a cooperative mode of operation."

The information obtained from the two hearings was thoroughly reviewed by the U.S. Government's Working Group on Standards and Conformity Assessment (testing, certification, laboratory accreditation, quality assessment, etc.). The working group's suggestions were embodied in the recommendations of the U.S. Government's Interagency Task Force on EC-92, the principal EC 92 trade policy development body of the U.S. Government. A section of the Task Force's Three Part Plan states that "...in association with the NIST workshops cosponsored with interested private sector groups on general issues of international interests in conformity assessment, the USG (U.S. Government) should take advantage of this opportunity to seek the potential needs of industry to EC 1992 'new approach' testing and certification."

In consultation with NIST officials, representatives of the American Council of Independent Laboratories (ACIL) and the American Electronics Association (AEA) organized a workshop panel consisting of experts from testing laboratories, trade associations, professional societies, manufacturers' representatives, standards organizations and Government. A principal reason for selecting electromagnetic compatibility as the topic for the second of these workshops was that the corresponding EC directive will be implemented by January 1, 1992. (A list of the panel members and attendees is in Appendix A.)

On February 28, 1991, NIST published a Federal Register Notice (Appendix B) outlining the purpose and agenda for the workshop and inviting interested parties to attend and observe. Including the panel, 54 persons attended the workshop. 
The purpose of this workshop on conformity assessment, which focused on information technology equipment (ITE), was to explore how the U.S. Government can assist the EMC sector in gaining acceptance of EMC test results in such international markets as the European Community. The workshop was held on April 4, 1991, in the U.S. Department of Commerce building, Washington D.C.

This report was prepared by NIST, circulated for comment to the panelists, and put in final form to accommodate appropriate comments.

\section{Panel Presentations}

\section{Dr. John W. Lyons, Director National Institute of Standards and Technology}

In opening remarks Dr. Lyons welcomed the participants. He stated that this important second sectoral workshop with the private sector was an outcome of the April 1990 NIST hearings. He conveyed the Secretary of Commerce's view that EC 92 presents a top priority challenge to increase the volume of U.S. exports. The United States currently exports to the EC alone about $\$ 95$ billion annually. The total annual U.S. exports throughout the world constitutes only 7 percent of our Gross National Product (GNP), whereas our major trading partners export approximately 19 percent of their GNP's: the U.S. figure must be increased.

Dr. Lyons added that: (1) increasing U.S. exports to the EC means getting our standard and conformity assessment in order; and (2) the United States needs to find ways to assure transparency with our EC partners in standards development and conformity assessment. Transparency will also help us to monitor standards and conformity assessment procedures for products which are regulated in the EC and unregulated here.

Dr. Lyons concluded his remarks by urging the panelists to develop recommendations on how the U.S. Government should contribute to solving these and other issues.

Charles M. Ludolph, Director, Office of European Community Affairs, International Trade Administration, Department of Commerce

Mr. Ludolph presented an overview of the European Community program for conformity assessment. It is expected that the EC electromagnetic compatibility directive will be implemented and directly applied to the commercial market on January, 1, 1992. The directive covers all apparatus liable to cause electromagnetic disturbance, or be affected by it, including electrical consumer products, such as radios, television sets, domestic appliances, etc. Certain industrial manufacturing equipment, mobile radios, information technology devices, telecommunications equipment, and scientific apparatus are also affected by the directive. The two basic requirements for adhering to the directive are that: 
(1) radiation generated by the apparatus must not interfere with the operation of radio and telephone equipment; and (2) all apparatus must have adequate immunity from electromagnetic disturbances.

Once the directive has been implemented, Mr. Ludolph added, it will be a manufacturer's responsibility to assure conformance which can be demonstrated by one of the following methods:

(1) A manufacturer provides a declaration of conformity (the European equivalent of selfcertification), stating that the manufacturer designed the equipment to conform to standards developed by the European Committee for Electrotechnical Standardization (CENELEC).

(2) The manufacturer prepares a "technical construction file" in advance of marketing the product, including a "technical report" from an independent "competent body" appointed by an EC member. This "competent body" may be an independent laboratory or a manufacturer's test facility. The manufacturer must keep these records available in Europe for 10 years following introduction of the product into the marketplace.

(3) For telecommunications terminal equipment and radio transmitters, the manufacturer obtains an "EC type examination" from a "notified body" designated by an EC member.

Due to delay in developing these European standards, many companies don't yet know how to design or redesign their equipment to meet the requirements of the directive.

Mr. Ludolph stated that the EC does not currently provide for a system of conformity assessment to be carried out in non-EC countries, such as the United States. EC conformity assessment is largely the responsibility of notified bodies, which at this time can be designated only within the EC. No subsidiaries or related enterprises located in a non-EC country can perform third-party certification. Early in 1991, the EC is expected to finalize its policy on non-EC country access to its conformity assessment systems, perhaps including ways of conferring subcontractor or notified body status outside the EC.

In conclusion, Mr. Ludolph stated that, since many of the pertinent EMC standards are yet to be developed, the EC is expected to amend the directive to provide a four-year transition period. This means that on January 1, 1992, manufacturers can choose to: (1) comply with all requirements of the directive and affixing the $\mathrm{CE}$ mark (the EC mark indicating conformance with provisions of a directive), or (2) continue to market their products under existing national regulations.

The full text of Mr. Ludolph's remarks is in Appendix C1. 
Mark Z. Orr, Deputy Assistant U.S. Trade Representative for Europe and the Mediterranean

Mr. Orr stated his interest as to whether the EMC community thinks it would benefit from mutual recognition agreements on conformity assessment: (1) between EC entities and U.S. laboratories, or (2) from product certifiers. The U.S. Government's role in relation to the private sector is a key question that the workshop panelists should address.

Mr. Orr added that the broad plan for the EC testing and certification system, as set out in the 1989 "Global Approach," amounts to a major undertaking and is not proceeding as rapidly as originally envisioned. If the system is not implemented in an open, nondiscriminatory manner, it could cause serious disruptions in trade flows. As presently proposed, the system stipulates that conformity assessment testing will be performed only by notified bodies within the EC. This policy could place U.S. manufacturers at a competitive disadvantage vis-à-vis European competitors. The U.S. objective is to secure access for manufacturer and conformity assessment entities and to ensure that they receive national (that is, equal) treatment in the $\mathrm{EC}$ market.

Possible solutions are: (1) self certification, the least disruptive and most cost efficient means, which may be applicable to some, although not all, product sectors; (2) subcontracting by EC notified bodies to entities outside the EC, a potential cost-reducing solution which would provide some measure of access for conformity assessment entities; and (3) mutual recognition agreements between the EC and its trading partners in specific industrial sectors. Here the role of the U.S. Government in relation to the private sector will have to be defined, since the EC will likely require a "guarantor" of the competency of notified bodies in the United States.

Mr. Orr stated that he considers the issues before the EMC workshop of great importance. Recommendations from this, and other sectoral workshops, will be used to make informed decisions on how the United States should proceed in negotiations with its trading partners in the area of conformity assessment.

The full text of Mr. Orr's remarks is in Appendix C2.

Julius P. Knapp, Deputy Chief, Authorization and Evaluation Division, Office of Engineering and Technology, Federal Communications Commission

Mr. Knapp described the EMC standards under current Federal Communications Commission (FCC) regulations. These standards are developed through rule-making in accordance with the Administrative Procedures Act, allowing for comment from any domestic or foreign party. FCC standards are generally consistent with international standards, but there are exceptions, such as the requirements for limiting noise for computer equipment. 
Compliance with applicable standards is assured with the help of an FCC authorization program for various types of equipment. To qualify for equipment authorization, a manufacturer files an application along with a measurement report that demonstrates compliance with the relevant technical standard. After successful review, the FCC issues a grant of equipment authorization within fifty days of the filing date. The FCC may elect to test samples of the equipment at any time. Compliance measurements may be performed by any party, domestic or foreign, and there is no requirement for laboratory accreditation. Instead, the FCC requires a one-time filing of a test site description, updated at least once every three years. In contrast to requirements in an accreditation program, no finding is made regarding the competence of test site personnel.

International mutual recognition agreements for equipment authorization present complex technical, policy, and legal issues. In Mr. Knapp's opinion, it is unlikely that the FCC will establish a separate EMC laboratory accreditation program due to lack of resources. The FCC might use NIST's National Voluntary Laboratory Accreditation Program (NVLAP). It is also conceivable that the private sector could implement its own accreditation program for EMC laboratories.

The full text of Mr. Knapp's comments is in Appendix C3.

\section{Judson C. French, Director, Electronics and Electrical Engineering Laboratory, National Institute of Standards and Technology}

Mr. French indicated his role at the workshop was oriented to technical support rather than policy development and described the functions of the Electronics and Electrical Engineering Laboratory (EEEL) in supporting the electronics industry, its customers, and Federal agencies. In particular EEEL addresses measurement research and services for: (1) basic electrical standards; (2) low frequency electronic instrumentation and the power community; (3) fiber-optics and lasers, superconductors and magnetics; (4) semiconductor materials, processes and devices; (5) radio-frequency, microwave and millimeter-wave signals; and (6) electromagnetic compatibility (EMC).

Mr. French identified the technical role of EEEL in EMC, including support of NVLAP in its development of an EMC accreditation program. EEEL also participates in international measurement comparisons to assure comparability of NIST measurements with laboratories of other nations.

Mr. French stated that he came to the EMC workshop to hear what the industry wants to do for itself and what NIST might do in the technical area to help industry compete successfully in international markets.

The full text of Mr. French's presentation is in Appendix C4. 


\section{Walter A. Poggi, President, Retlif Testing Laboratories.}

Mr. Poggi stated that: (1) the Europeans place greater emphasis on testing and certification than does the United States; (2) the openness of the FCC to foreign-generated test data is not mirrored by the EC; (3) the policy set forth by the EC may, if implemented, lead to economic and logistic hardship (if not to trade barriers) to U.S. manufacturers; and (4) the EC policy of total or partial non-acceptance of U.S.-generated test data will have a devastating effect on the U.S. independent testing laboratory community.

The EC policy on subcontracting by an EC notified body to a non-Ec entity does not seem to be promising because, in his opinion, this process could lead to a restraint of trade and potential discrimination against small U.S. laboratories.

Mr. Poggi urged the panel to set forth clear and unified positions on the subject of conformity assessment policies.

The full text of Mr. Poggi's presentation is in Appendix D1.

\section{James Wm. Johnson, Associate and Chief Executive Officer, Amador Corporation}

Mr. Johnson stated that January 1, 1993, will mark a profound change for the U.S. testing and certification community, of which his company is a member. Improvement in U.S. technology is vital to ensure the continued ability of U.S. manufacturers of electronic equipment to export to the EC. U.S. Government participation in conformity-assessment related negotiations with the Europeans is critical to assure uniform EC/U.S. testing and certification quality. U.S.-based entities should be able to qualify as notified bodies, and NIST's NVLAP should be used for EMC laboratory accreditation.

Mr. Johnson believes that the FCC should change its policy by adopting appropriate international standards to enable U.S. electronic firms and EMC testing labs to become recognized as world-class institutions. The U.S. Department of Commerce (DOC) should adopt an aggressive position of encouraging U.S. Government oversight in areas of conformity assessment.

Mr. Johnson concluded by stating that the EMC workshop is a valuable forum for making specific recommendations for changes affecting the EMC conformity assessment sector vis-àvis the emerging $\mathrm{EC}$ environment.

The full text of Mr. Johnson's presentation is in Appendix D2. 


\section{Glen Dash, Dash, Straus and Goodhue, Inc.}

Mr. Dash presented an overview of the EMC directive. Equipment conformance with the electromagnetic compatibility directive will require that: (1) no generated electromagnetic disturbance prevents radio, telecommunications equipment and other apparatus from operating as intended; and (2) apparatus shall have an adequate level of intrinsic immunity to electromagnetic disturbance.

Mr. Dash described specific technical EMC specifications, including: (1) standards framework, (2) emission limits, (3) proposed radiated immunity limits, and (4) waveform parameters.

The full text of Mr. Dash's presentation in Appendix D3.

Keith Mowry, Assistant to the Vice President, Governmental Affairs, Underwriters Laboratories

Mr. Mowry stated that products subject to EMC requirements in the EC are also regulated in the United States by the FCC. On the other hand, there are many U.S. private sector safety certification programs for other attributes of products that are for the most part regulated in the EC, but not in the United States. The options available to assist exporters will necessarily differ depending on the specific requirements that must be met.

Mr. Mowry addressed the questions in the Federal Register Notice (Appendix B). He proposed that the U.S. Government "integrate" private sector views when negotiating with the EC, ensuring that domestic safety considerations and the needs of exporting manufacturers are met.

The full text of Mr. Mowry's presentation is in Appendix D4.

\section{H.R. Hofmann, AT\&T, Bell Laboratories}

Mr. Hofmann described the following concerns of the Computer and Business Equipment Manufacturers Association (CBEMA) relating to the EMC directive: (1) timely development of standards for emissions and immunity; (2) adequate phase-in period for applying the standards; (3) development of standards for testing sites; (4) provision of full recognition of U.S. EMC test houses; (5) equal/full recognition of manufacturers test sites; (6) harmonization of limits and test procedures; (7) establishment of full reciprocity with the EC; (8) setting appropriate standards for different equipment types; and (9) allowing manufacturers' declarations of conformance to standards.

The full text of Mr. Hofmann's presentation is in Appendix D5. 
Dr. Matejic reported on the development status of EN (European Norm) 55022. New standards are expected to create a backlog in European laboratories. He noted that no provisions have been made to have notified laboratories outside EC member states. The small number of RFI (radio frequency interference) laboratories in Europe is not sufficient to support prototype testing for U.S. companies. It is therefore crucial to provide EC recognition of U.S. test data. This could be accomplished by EC accreditation of U.S. company-owned and independent laboratories. FCC test procedures need to be harmonized with those of the IEC (International Electrotechnical Commission) and the CISPR (International Special Committee on Radio Interference).

Dr. Matejic recommended a coordinated effort of U.S. interests in the EMC conformity assessment area to ensure cost reduction and timely exporting of U.S. products.

The full text of Dr. Matejic's presentation is in Appendix D6.

\section{Peter Boers, Senior Engineering Manager, Digital Equipment Corporation}

Mr. Boers stated his view that the proposed EC regulations present no technical problems for U.S. industry. However, firms that don't have test facilities in the EC may experience a serious negative impact. Firms outside the EC will be required to have their prototypes tested by EC notified bodies before products can be exported. This delay imposes a serious handicap to U.S. firms in their attempts to succeed in a market which deals in short-lifecycle, high-technology products.

Mr. Boers recommended two alternative solutions: (1) manufacturer's self certification (supported by Digital Equipment Corporation); or (2) establishment of full reciprocity between the EC and the United States.

The full text of Mr. Boers's presentation in Appendix D7.

\section{Responses to Questions from the Audience}

During the workshop, persons in the audience were invited to submit written questions to the chairman for response by appropriate panel members. The questions and responses are summarized below. 
Question: Can a U.S.-based entity qualify as a notified body or competent laboratory?

Answer: There is currently no provision for a U.S.-based entity to qualify as a notified body or competent laboratory.

Question: What are the criteria for gaining notified body status using EN 29000 (European Norm-Quality Systems) and EN 45000 (European Norm-Conformity Assessment) series of standards?

Answer: To gain notified body status in the EC, it is necessary to be under legal EC jurisdiction, which at this time would require relocating the laboratory to Europe.

Question: (1) What are the chances of using manufacturers' declarations of conformity for demonstrating compliance with the EMC directive?

(2) Will manufacturers' declarations of conformity be permitted in accordance with the DTI (Department of Trade and Industry, United Kingdom) telecom equipment directive?

Answer: The DTI telecom directive is being revised, and it appears that mandatory EMC requirements will be included. A number of industry representatives argued unsuccessfully before the European Commission that manufacturers' declarations of conformance (as specified in the product safety directive) have worked well in the past. The informal answer from the Commission was that the product safety directive may have to be revised. The present trend seems to be in the direction of third-party certification.

Question: How is 89/336/EEC (European Council Directive on the Approximation of the Laws of the Member States relating to Electromagnetic Compatibility) related to ISO 9000 (International Organization for Standardization-Quality Systems)?

Answer: Both 89/336/EEC and ISO 9000 include "horizontal requirements affecting many product sectors. ISO 9000 is not required or referenced with respect to the EMC directive. Labs performing tests must themselves have good quality control. These elements are spelled out in EN 45000 (Standards for Conformity Assessment), or ISO Guide 25 (General-Requirements for the Technical Competence of Testing Laboratories). 
Question: Should the FCC test site listing program and NVLAP be combined?

Answer: NVLAP is an existing NIST program and is working well. Representatives of independent test laboratories, who currently participate in this program, support NVLAP and would like to see it continue to grow. The FCC would welcome a petition from the private sector on this subject.

Question: Is an accreditation program preferable and, if so, should it be under NVLAP or a private sector program?

Answer: The issue of whether a private accreditation program should be established is difficult to answer without thorough examination of all factors, such as the increased cost which would be borne by the manufacturers and their customers. Input should be sought from all interested parties before a decision is made.

Question: Would inclusion in the GATT (General Agreement on Tariffs and Trade) of a code of conduct for conformity assessment entities, similar to that for standards developers, help to open up the EC testing and certification system for regulated products?

Answer: The code of good practice for standards is voluntary, but there has been some movement to expand the coverage to testing and certification with regard to transparency. This may be a subject for exploration as the work program for the standards code is developed during the post Uruguay-round period.

Question: Would the FCC consider closing off listing to non-U.S. (e.g., European) firms in retaliation for an EC market closed to U.S. testers?

Answer: There is no simple answer: the issue goes beyond the basic FCC mission of regulating telecommunications. Due to political, trade, and legal concerns, it is unlikely that the FCC would take such a step.

Question: Would test laboratory representatives support such a step?

Answer: Yes, they will support any such FCC action. 
Question: How can one get more specific information on current and prospective requirements issued by the $\mathrm{EC}$ ?

Answer: The following sources are recommended: (1) The Official Journal of the European Community available from the Delegation of the Commission of the European Communities, 2100 M Street, N.W., Washington, D.C. 20036, which lists notified bodies, standards, and council recommendations; (2) The CENELEC (European Committee for Electrotechnical Standardization) Memorandum published monthly by the American National Standards Institute, 11 West 42nd Street, New York, NY 10036, which lists all CEN (European Committee for Standardization) and CENELEC standards and the status of their development); (3) membership in CISPR, whose address is: British Electrotechnical Committee, British Standards Institution, 2 Park Street, London W1A 2BS, United Kingdom; and (4) equipment vendors who keep up-to-date information on standards development in Europe.

\section{Recommendations}

Based on the above discussion and recommendations extracted from the presentations of the private sector panelists, Chairman Poggi presented a number of candidate statements to the panel for workshop adoption as the representative views of the EMC sector. In adopting these recommendations ${ }^{1}$, it was the consensus of the private sector panelists that they should constitute the initial agenda for an EMC sectoral advisory committee.

1. The U.S. Government should establish an electromagnetic compatibility (EMC) sectoral advisory committee, composed of all interested parties, to assist in the development of positions for use as a basis for negotiations with the European Community (EC) on matters relating to conformity assessment.

2. The National Voluntary Laboratory Accreditation Program (NVLAP) and the Federal Communications Commission (FCC) should harmonize existing EMC accreditation programs.

3. The U.S. Government should negotiate an agreement with the European Commission making it possible to designate notified bodies for the EMC sector in the United States.

'The Underwriters Laboratories (UL) representative did not endorse these statements as recommendations, but did consider them appropriate for more detailed discussions by an advisory committee. 
4. The U.S. Government should take a formal role in accrediting conformity assessment programs as a means of satisfying European Community directives.

5. The National Institute of Standards and Technology should take a proactive role in disseminating information to affected interests in the EMC area. 


\section{Future Actions}

Based on the results of this workshop, the workshop on pressure vessels, and future workshops, NIST will collect and review recommendations to determine how the U.S. Government can best assist the private sector in gaining acceptance of U.S. products abroad. Information will be transmitted to cognizant authorities for selection of the most appropriate courses of action.

Other workshop topics under consideration are: plywood, softwood lumber and other wood products; wood windows and doors; machine tools; and personal protective devices. 

Appendix A

Panel Members and Attendees 

EMC Workshop Panel

Bill Bartley

Zeos International

530 5th Ave. NE, Ste. 1000

New Brighton, MN 55112

Peter Boers

Sr. Eng. Manager

Digital Equipment Corporation

146 Main St., ML06 $1 /$ U30

Maynard, MA 01754

Michael Britko

Mgr., Compliance Engineering

Wang Laboratories

Mail stop 015-15A

One Industrial Ave.

Lowel1, MA 01851

Milton Bush

Director of Public Affairs

American Council of Independent Laboratories

$1725 \mathrm{~K} \mathrm{St}$. NW

Washington, DC 20006

Glen Dash

Director

Dash, Straus and Goodhue Inc.

593 Massachusetts Ave.

Boxborough, Ma 01719

Judson French

Dir., Electronics \& Elec. Eng. Lab.

National Institute of Standards and Technology

Gaithersburg, MD 20899

H. R. Hofmann

Chm., CBEMA Committee ESC 5

AT\&T Bell Laboratories

2000 N. Naperville Rd., Rm. 2B220

Naperville, IL 60566

James Wm. Johnson

CEO

Amador Corporation

Corporate Headquarters

Taylor Falls, MN 55084

Julius Knapp

Deputy Chf., Auth. \& Eval. Div.

Federal Communications Commission

7435 Oakland Mills Rd.

Columbia, MD 21046

Charles Ludolph

Dir. Office of EC Affairs

International Trade

Administration, DOC

Hoover Bldg., Rm. 3036

Washington, DC 20230
Mirko Matejic

Consulting Engineer

Codex-Motorola

Mail stop C1-20

20 Cabot Blvd.

Mansfield, MA 02048

Michael Mosca

Mgr., Compliance Engineering

Proteon Inc.

Two Technology Dr.

Westborough, MA 01581

Keith Mowry

Asst. to VP, Gov. Affairs

Underwriters Laboratories

81818 th St. NW, Ste. 400

Washington, DC 20006

Mark Z. Orr

Deputy Assistant USTR for Europe and the Mediterranean

office of the U.S. Trade

Representative

600 17th St. NW

Washington, DC 20506

Walter A. Poggi

President

Retlif Testing Laboratories

795 Marconi Ave.

Ronkonkoma, NY 11779

Eric Schimmel

Vice President

Telecommunications Industry Assn.

2001 Pennsylvania Ave. NW, Ste. 800

Washington, DC 20006

Bert Simson

Sr. Advisor, Off. of stds. Services

National Institute of Standards and Technology

Gaithersburg, MD 20899

Stanley I. Warshaw

Dir., Off. of Stds. Services

National Institute of Standards and Technology

Gaithersburg, MD 20899

Brian Wynne

Sr. Mgr., Intl. Trade Affairs

American Electronics Association

1225 Eye St. NW, Ste. 950

Washington, DC 20005 
Mel Altman

Center for Devices and

Radiological Health

Food and Drug Admin. (HFZ-80)

Rockville, MD 20857

David Blocksom

Certitech Corp.

P.O. Box 300

Running springs, CA 92382

Joseph Butler

Chomerics, Inc.

77 Dragon Court

Woburn, MA 01888

Mike Caldwell

Scientific-Atlanta, Inc.

3845 Pleasantdale Rd., M/S ATL 11-Q

Atlanta, GA 30340

John Curry

MET Electrical Testing Company, Inc.

916 West Patapsco Ave.

Baltimore, $\mathrm{MD} 21230$

Tim D'Arcangelis

Instruments for Industry, Inc.

731 Union Parkway

Ronkonkoma, NY 11779

Russell Grant

Certelecom Labs

820 Proctor Ave.

Ogdensburg, NY 13669

Sara Hagigh

International Trade Admin./DOC

Room 3036

Washington, DC 20230

Susan Hegerich

Am. Council of Indep. Labs.

$1725 \mathrm{~K}$ street NW, \#412

Washington, DC 20006

\section{Dana Heyman}

Am. Council of Indep. Labs.

$1725 \mathrm{~K}$ street NW

Washington, DC 20006

Jeffrey Horlick

National Institute of standards and Technology

Gaithersburg, MD 20899

Rex Johnson

Scientific-Atlanta

Broadband Communications Group

4386 Park Drive

Norcross, GA 30093
Ralph H. Justus

Electronic Industries Association

2001 Pennsylvania Ave. NW

Washington, DC 20006

Motohisa Kanda

National Institute of standards and Technology

Mail stop 813.03

325 Broadway

Boulder, Co 80303

George Kavelak

IBM Corporation

Entry Systems Div.

1000 Northwest 51 st st.

Boca Raton, FL 33432

George F. Kimmerling

Laboratopry Regulation News

Buraff Publications

1350 Connecticut Ave. NW, ste. 1000

Washington, DC 20036

Ray Klouda

Elite Electronics

1516 Centre Circle Dr.

Downers Grove, IL 60515

Walter F. Kozikowski

National Electrical Manufacturers Association

2101 I street NW, ste. 300

Washington, DC 20037

Walter Leight

National Institute of standards and Technology

Gaithersburg, MD 20899

Bernie Liebler

Health Industry Mfrs. Assn.

103015 th street NW

Washington, DC 20005

Dr. John W. Lyons

Director

National Institute of Standards and Technology

Gaithersburg, MD 20899

Donald R. Mackay

Air-Conditioning \& Regrig. Inst.

1501 Wilson Blvd., Ste. 600

Arlington, VA 22209

J. Franklin Mayo-Wells

National Institute of standards and Technology

Gaithersburg, MD 20899 
John Mentis

National Forest products Assn.

1250 Connecticut Ave. NW, Ste. 200

Washington, DC 20036

Donald L. Peyton

Consultant

Two Beverly Rd.

white plains, NY 10605

Roger Rensberger

National Institute of Standards and Technology

Gaithersburg, MD 20899

Harvey schock

Consultant

30 Oak Ridge Drive

Haddonfield, NJ 08033-3507

Lawrence Schwartz

Retlif Testing Laboratories

795 Marconi Ave.

Ronkonkoma, NY 11779

Leonard Shanhon

Wilmer, Cutler \& Pickering

2445 M street NW

Washington, DC 20037

Anna snow

Delegation of the Commission of the European Communities

$2100 \mathrm{M}$ street NW, 7th Fl.

Washington, DC 20037

William sperber

General Motors Corporation

EMC -40

General Motors Proving Grounds

Milford, MI 48380-3726

Donald Sweeney

DLs Electronic systems, Inc.

10350 Dearlove Rd.

Glenview, II 60025

Nancy M. Trahey

National Institute of Standards and Technology

Gaithersburg, MD 20899

George E. Walton

American Association of Motor

Vehicle Administrators

4200 Wilson Boulevard, Ste. 600

Arlington, VA 22203

Gina Zivkovic

Digital Video Systems Corp.

Canadian Div. of Scientific-Atlanta

120 Milldefield Rd., \#1

Scarborough, ontario

Canada M1S 4M6 

Appendix B

Federal Register Notice 

National Institute of Standards and Technology

Improving Acceptance of U.S. Products in Internatlonal Markets; Opportunity for Interested Parties To Attend and Observe

AGENCY: National Institute of Standards and Technology, Commerce.

ACTION: Notice of workshop.

SUMaAary: This is to advise the public that the National Institute of Standards and Technology (NIST) is cosponsoring an Electromagnetic Compatibility Workshop with the American Council of Independent Laboratories and the American Electronics Association. This is the second in a series of workshops designed to gather information, insights, and comments to determine conformity assessment related activities (testing. certification, accreditation, quality assessment, etc.) in which the U.S. Government can assist U.S. industry in gaining product acceptance within other markets such as the European

Community (EC). Suggestions for future workshops are invited.

DATES: The workshop will be held at 9:30 a.m. on Thursday, April 4, 1991. The request to attend should be received by March 22, 1991.

ADDRESSES: The workshop will be held in the Auditorium at the U.S.

Department of Commerce, 14th Street and Constitution Avenue NW., Washington, DC 20230.

FOR FURTHER INFORMATION CONTACT: Mr. Bert G. Simson, Office of Standards Services, National Institute of Standards and Technology. Administration Building, room A-603, Gaithersburg, MD 20899; (301-975-4008).

SUPPLEMENTARY INFORMATION:

Consistent with the growing importance of international standardization to the United States, NIST is cosponsoring an Electromagnetic Compatibility

Workshop with the American Council of Independent Laboratories and the American Electronics Association to solicit views and recommendations on how the U.S. Government can assist this sector of U.S. industry in gaining product acceptance within international markets such as the EC.

Tentative topics for discussion at the workshop are listed below. Sponsors of individual workshops may identify specific issues focused on their sectors.

1 Which EC requirements for conformity assessment are applicable to your sector?

2. Do the European regional standards (CEN/CENELEC/ETSI) or international standards (ISO. IEC. CCITT) that apply to your sector differ from U.S. standards?

3. To what extent do you feel that U.S. conformity assessment systems relating to your sector are adequate for acceptance of test data or other attestations of conformity by the EC member states?

4. Would your sector benefit from developing mutual recognition agreements between U.S. laboratories or product certifiers and their EC counterparts?

5. How can the U.S. Government better utilize private sector input when developing official positions with regard to possible negotiations with the EC for your sector for regulated products?

6. Should "CE" marks of conformity be made acceptable in the U.S.

marketplace? What are the liability implications of such acceptance?

7. Does your sector need a recognizable mark of conformity? Is a U.S. mark needed?

The workshop will be held at 9:30 a.m. on April 4, 1991, in the Auditorium at the U.S. Department of Commerce, 14th Street and Constitution Avenue, N.W., Washington, DC 20230. To guarantee space, persons who wish to attend and observe the workshop should submit a notice in writing to Mr. Bert G. Simson, Office of Standard Services, National Institute of Standards and Technology, Administration Building, room A-603, Gaithersburg, MD 20899. Requests should contain the person's name, address, telephone and facsimile numbers, and affiliations. Requests should be received by March 22, 1991.

Dated: February 19, 1991.

John W. Lyons,

Director.

[FR Doc. 01-4402 Filed 2-25-91; 8:45 am] EUUNO CODE 3510-13-M 


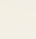




\section{Appendix C}

Presentations by U.S. Government Representatives 



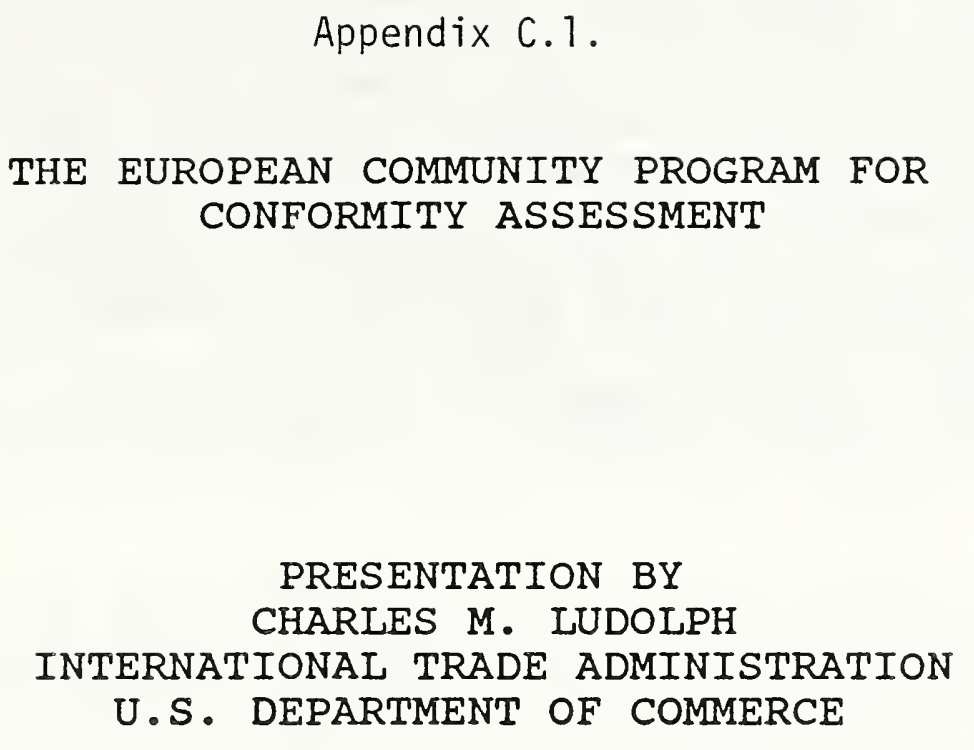

THE EUROPEAN COMMUNITY PROGRAM FOR CONFORMITY ASSESSMENT

\author{
PRESENTATION BY \\ CHARLES M. LUDOLPH \\ INTERNATIONAL TRADE ADMINISTRATION \\ U.S. DEPARTMENT OF COMMERCE
}

\begin{abstract}
THE ACIL/AEA/NIST WORKSHOP ON
ELECTROMAGNETIC COMPATIBILITY

"IMPROVING ACCEPTANCE OF U.S. PRODUCTS IN

INTERNATIONAL MARKETS"

WASHINGTON, D.C.
\end{abstract}

APRIL 4, 1991 
OVERVIEW Safety and health is a primary focus in both EC directives and and in standards and testing methods. The European Community intends to establish a system that harmonizes the national legal requirements for safety and health in sensitive product sectors through one set of harmonized product safety legislation, new European product standards, and a unified European mandatory conformity assessment program. In the electromagnetic compatibility area, sectors covered under the "old Approach" of mandatory standards and government approvals are automobiles and telecommunications. The EC has also adopted a "New Approach" directive covering electromagnetic compatibility for all products.

The New Approach directive on EMC was adopted by the European Community as law in May 1989 - 89/336/EEC on the Aproximation of laws on Electromagnetic Compatibility. It is expected that most, if not all, EC member states will adopt implementing national legislation by July 1991 and that the directive will be implemented and directly applied to the commercial market on January, 11992 -- little more than eight months from now.

The EMC directive covers all apparatus liable to casue electromagnetic disturbance or be affected by electromagnetic disturbances. Virtually all consumer electronic products are covered - radio and television, domestic appliances, lights and flourescent lamps; as well as industrial manufacturing equipment, mobile radios, information technology devices, telecommunications equipment and scientific apparatus. Components creating an EM disturbance which are for speciific purposes are also covered.

Excluded from the directive because they are already covered elsewhere are motor vehicle spark ignition and electric meters. Since the EC expects directives on non-automatic weighingmachines and medical devices with EMC elements these also are excluded.

There are two basic requirements for adherence to the directive: a) radiation generated by apparatus must allow radio and telephone equipment to operate and b) all apparatus must have adequate immunity from EM disturbances.

The directive, when fully applied will require all further production of existing designs and all new products to be marketed in accordance with the basic requirements in the directive. 
It is the responsibility of the manufacturer to insure the directive is complied with. In most cases, these means that the manufacturer must choose one of two routes to comply with the requirements of the directive. First, the manufacturer may choose what can be thought of as a European version of "self-certification." In this case, the manufacturer designs the products to conform to specifically designated European standards developed particularly to be applied to this directive by the European regional standards body, committee for European Electro-technical Normalization (CENELEC). The manufacturer, in this case, may declare conformity to these CENELEC standards and be assured of the ability to continue his product.

Alternatively, the manufacturex may choose to ignore all or some of the European standards and seek to demonstrate conformity to the essential requirements listed in the Annex to 89/336/EEC. In this case, a "technical construction file" must be prepared in advance of marketing the product. The file describes the apparatus, sets out the procedures used to ensure conformance of the product to the essential requirements, and includes a "technical report" from an independent "competent body." A competent body may be an independent laboratory or the manufacturers own test facility that is capable of performing the operations. This file must be held available in Europe for 10 years from the introduction to the market of the apparatus.

In the case of the telcommunications terminal equipment and radio transmitters covered by this directive, the manufacturer must obtain an "EC-type examination" from a "notified body." A notified body is an independent test facility deemed capable of performing the examination. Lists of European notified bodies and competent bodies to perform these activities are notified by the European government, their capability is guaranteed by EC member states and the names are listed in the official register of the EC Commission in order to inform the public particularly customs officials as to who can legitimately attest.

The result of these attestations to standards and requirements and creation of technical files and so on is that the manufacturer can affix the "CE mark" to their product. The CE mark includes the year of affixation and a designation of the "body" performing the required functions. "Self-certification carries no designation since there is no "body." This may cause a commercial perception of a difference in a product with a test $\mathrm{lab}$ associated with it in some countries. There is a criminal penalty for marketing products without the required mark and also a penalty to fraudulently affix the mark to a product not covered by a "New Approach" directive. 
So what happens on January 1, 1992? All the prerequisites upon which the EMC directive rests may indeed be in place on January 1, 1992. CENELEC is in the process of developing 30 new standards and revising 120 existing standards. If they can keep to their schedule, standards will be available in 1992 that will support the manufacturer's declaration of conformity module (self certification). Adequate test facilities is another matter. Manufacturer's facilities or independent test labs competent to perform the radiation and susceptibility tests are very few in Europe. Most importantly, the relative lateness of standards development means that many companies have no idea how to redesign their equipment to meet the requirements of the directive.

Taking account of these shortcomings, the EC is expected to issue an amendment to the EC directive that provides for a four year transition. That is, on January 1, 1992, manufacturers will be able to choose between complying with the full requirements of the directive and affix the $c E$ mark which guarantees free circulation of the goods throughout the entire European community or remain marketing the products under the existing national regulations. As proposed, this option of compliance with national requirements in existence before January 1, 1992 is available for four years, until January 1, 1996. At that time, all manufacturers must be in full compliance with the EC directive.

EC Testing and Certification Procedures:

How Will They Work? Generally the EC provides for a system of conformity assessment that at this time does not provide for conformity assessment to be carried out in the United states. In fact, EC conformity assessment is largely the responsibility of notified bodies which are entities in the EC designated as fully capable to perform the role of "competent bodies" or "notified bodies" required in the EMC directive.

The EC's Global Approach to testing and certification for product safety is intended to provide producers with one set of procedures for certifying product compliance with EC legal requirements. EC legislation sets minimum legal health, safety and environmental requirements for products ranging from toys to machinery to medical devices. The legislation specifies various means by which manufacturers can certify product conformance. Options include manufacturer self-declaration of conformity, third party testing, quality assurance audit and/or full type approval by a body authorized by an EC member state and recognized by the EC Commission. A "CE" mark on the product signifies that all legal requirements have been met. 
Many manufacturers will have to meet the requirements of more than one directive in certifying product conformity. Take the situation for a manufacturer of information technology equipment, for example. EC requirements for this equipment are covered under four separate directives - the EMC directive, the low voltage directive (electrical safety), the telecommunications terminal equipment directive, and the ergonomics directive for visual display terminals. Product certification could involve some combination of in-house safety testing, audit of the manufacturer's production quality assurance system, and type examination by a third party certifier

Reference to harmonized European standards relevant to EC legal safety requirements provides manufacturers the simplest route to product certification. These standards are now being developed by regional standards organizations, the European Committee for Standardization (CEN), the European Committee for Electrotechnical Standardization (CENELEC), and the European Telecommunications Standards Institute (ETSI). Manufacturers are free to refer to other standards in certifying compliance, but the certification process will be more complicated. The Community views European standards as critical to the effectiveness of their planned testing and certification system; so much so that implementation of the EMC directive may be postponed.

Who Can Certify? All EC product safety directives provide for some third party role in testing or certification. For several - 6 of 9 directives already adopted - this is mandatory. EC member states are responsible for determining the competence of test labs and certification bodies that apply for recognition under the EC system. Approval is at the member state level, according to recognized accreditation procedures, based on the EN 45000 series of standards. Member states notify their selections - thus the term "notified" bodies - by task and by directive, to the EC Commission, which has the right to request information from member states on the competence of bodies and can require verification of qualifications.

On their own responsibility, notified bodies in the EC can subcontract specific activities to extend their ability to perform. Subcontracting entities can be located outside of the EC. Conditions and limits have not been fully specified yet, but subcontracting of testing activities has been specifically permitted by the EC Council of Ministers. The general guidelines for subcontracting indicated by the EC Commission are that notified bodies will only need to hold subcontractors to EN 45000 standards, including the requirements to maintain records; that subcontractors must test to the same standards as the notified body; and that notified bodies remain responsible for any certification activity. 
Still up in the air are important issues such as whether any or all aspects of quality assurance audits can be subcontracted, how widely EC notified bodies will exercise their

subcontracting capabilities, and whether subcontracting arrangements will give U.S.-based manufacturers sufficient low-cost access to the EC market.

Product Certification Outside of the EC? Under the EC system member states can only designate notified bodies from within the EC. No subsidiaries or related enterprises located in a third country can perform third party certification, accreditations or approvals, except under a mutual recognition agreement with government authorities of that country.

According to EC Commission officials, any agreement would have to ensure that both parties obtain broadly equivalent opportunities to participate in each other's certification systems for the products concerned and thus similar opportunities for improved access to each other's markets. Agreements would have to include mechanisms for third country governments to guarantee that testing and certification bodies do their job properly and means for them to withdraw notification if they do not.

Developments Outside of Regulated sectors The EC is also promoting harmonization of testing and certification requirements in nonregulated areas, although the pace of this harmonization very much depends on intiatives in the European private sector. The comission has created a new organization called the European organization for Testing and certification (EOTC), established under a memorandum of agreement with CEN/CENELEC and the European Free Trade Association (EFTA) countries. The EOTC is intended to promote mutual recognition of tests, test and certification procedures, and quality systems within the European private sector for product areas or characteristics not covered by EC legislative requirements.

Current status In the area of testing and certification, the EC will be finalizing its policy on third country access to its conformity assessment system, including the area of mutual recognition agreements conferring notified body status. Action is expected in early 1991. A common position has been made on the modules section of the EC's Global Approach to Testing and certification. Adoption of this common position by the council is expected by the end of December. This section contains information on subcontracting. To date, the EC will allow subcontracting of testing but is hesitant to permit subcontracting of so-called "evaluative" functions (including quality assurance audits).

Plans for the new European Organization for Testing and Certification (EOTC), were finalized in the summer of 1990, and a director has been named. The EOTC, designed to be the focal point for testing and certification in the nonregulated sector, will consist of various sectoral committees and agreements groups. The EOTC plans to meet in the spring to more clearly define functions, structures, and scope. 
Another proposed new institution is the European

Standardization System (ESS), discussed in the Commission Green Paper. The ESS, designed to better coordinate standards work, would consist of a European Standards Council and a standards Board. The functions of these groups will be more clearly defined at a later date.

Remaining Areas of Significant Interest/Concern: The USG has some serious concerns in the area of proposed mutual recognition agreements (MRA's) which would confer notified body status to parties in the U.S. Our concerns include such issues as who would be the responsible body in the U.S. to enter into MRA's (government or private sector bodies), whether or not the USG would be responsible for guaranteeing the performance of notified bodies, and ultimately whether MRA's are in the best interest of the U.S.

The degree of directive implementation at the member state level continues to be a problem. A July 1990 Single Market tally shows that only 19 Council adoptions have been implemented by all 12 member states. The one new approach directive which has been implemented, toys, has been implemented in only 6 states. Problems exist with the toy directive, notably different member state interpretation on the degree to which self-certification can be used to show conformity to essential requirements. The Italians have said that self-certification of toys would not be applied in Italy.

The USG continues to press for increased transparency and access to European standards bodies, primarily CEN/CENELEC. Though agreements between ISO/CEN and IEC/CENELEC have resulted in increased information-sharing, the USG will continue to press for observer status in CEN/CENELEC.

For Further Information call office of European Community Affairs, International Trade Administration, Washington DC (202) 3775276 . 
Appendix C.2.

MARK Z. ORR

EMC WORKSHOP

April 4, 1991

- Speaking Notes -

I. INTRODUCTION

Important role of workshops

-- inform government of industry needs and concerns

-- ensure that industry has adequate information on which to make informed decisions and provide advice

Key questions set out in Federal Register notice

-- particularly interested in views on whether EMC community would benefit from mutual recognition agreements between U.S. laboratories or product certifiers and EC entities

-- If so, what role should the U.S. government play? What role should the private sector play?

Issue of standards, testing and certification in the single market is extremely important

- for many industries, will determine degree of access to the single market

-- the top priority issue for the U.S. Government with regard to the single market in 1991 and possibly beyond

-- important that the U.S. Government and the U.S. private sector work together closely to ensure that U.S. interests are addressed satisfactorily 
The broad outlines of the testing and certification system being created by the EC are by now familiar

-- set out in the 1989 "Global Approach" document and 1989 Council Declaration

- $\quad$ EOTC system for non-regulated sectors

\section{A few salient points:}

Establishing this system is a major undertaking, which is not proceeding as rapidly or as smoothly as originally envisioned by the EC Commission

- if constructed and implemented in an open, nondiscriminatory manner, system should facilitate trade flows with the community and between the community and its trading partners

- if not done in this manner, could cause disruptions in trade flows, increased costs for U.S. exporters, and result in U.S.-EC trade disputes

System as presently proposed denies foreign manufacturers and conformity assessment entities adequate access

-- proposed system requires that conformity assessment must be done by "notified bodies" within the EC

-- costly, time consuming, and often duplicative

Potentially places U.S. manufacturers at a competitive disadvantage vis-a-vis European competitors

-- must secure access to EC notified bodies

-- may limit ability to be first to market with new products

Also prevents U.S. conformity assessment entities from participating in conformity assessment activities for the single market

-- for small entities, this is a direct threat to their continued economic viability 
U.S. objective:

-- secure adequate access (for both U.S. manufacturers and conformity assessment entities) on sufficiently flexible terms

-- ensure that U.S. manufacturers and conformity assessment entities receive national treatment in the single market. 
III. POSSIBLE SOLUTIONS

A. SELF CERTIFICATION

As a general rule, to the greatest extent possible, EC directives for the single market should provide for manufacturers self-declaration of conformity with single market standards

-- easiest, least disruptive, cost-efficient means

-- may not be applicable in all product sectors 
EC currently contemplates subcontracting by notified bodies of certain activities to entities outside the community

- potentially a partial solution to concerns of U.S. manufacturers and conformity assessment entities

-- would reduce costs for manufacturers and provide a certain degree of access for conformity assessment entities

- remains to be seen how much interest there will be in such arrangements on the part of notified bodies in the EC and entities in the United States

Scope of permissible subcontracting activities is unclear and must be clarified

- testing only? and only by bodies authorized to do more than just testing?

-- evaluative functions?

- quality systems audits?

Provisions defining permissible subcontracting activities should not be the subject of negotiations between the EC and its trading partners

-- should be determined by regulation

Recent EC Commission working document represents an effort to clarify terms and conditions for subcontracting

-- a step in the right direction, but not clear how far

-- allows for the inclusion of quality assessment activities

-- but still maintains unreasonable limits on scope of permissible activities

-- also establishes artificial divisions of responsibility between notified bodies and sub-contractors

Without a more flexible approach, the economic incentive for European notified bodies to enter into subcontracting arrangements is not clear. 
C. MUTUAL RECOGNITION AGREEMENTS

Possibility exists for the conclusion of mutual recognition agreements between the EC and its trading partners in various sectors

-- a potential means for U.S. manufacturers to satisfy conformity assessment requirements for their products in the United States; and

-- for U.S. entities to engage in the full range of conformity assessment activities for the single market

As presently contemplated by the EC, the terms and conditions for mutual recognition agreements present a number of serious problems

-- involves the assumption of certain obligations by U.S. entities

-- implies acceptance of results of activities conducted by EC notified bodies and marks conveyed by them

-- meshing of different regulatory systems in which products may be regulated in the EC and not in the U.S. and vice-versa

Key question of role of government versus that of the private sector

-- EC will require a "guarantor" of the competency of "notified bodies" in the United States -- the U.S. government;

-- at present, this role is played by the private sector in most sectors

-- recent indications seem to suggest that the EC may be willing to accept an "equivalent" guarantor -- i.e., accreditation systems run by the U.S. private sector 
An insistence on reciprocity ("balanced situation")

-- conditioning access to the single market on reciprocity requirements is unacceptable to the U.S.

-- the U.S. market in general, and testing and certification schemes in particular, are open to EC products and firms

-- no additional "benefits" exist to be gained by the EC through such agreements

Recent EC Commission paper represents an effort to clarify some of these issues and suggests some flexibility

-- some clarification of the notion of "mutual benefits"

-- suggestion of the possible acceptance of private sector accreditation programs in lieu of a governmental guarantee of the competence of U.S. conformity assessment entities

-- potentially a step backward on the terms of a "balanced situation"

These issues will need to be addressed satisfactorily in order for the USG to determine whether entering into mutual recognition agreements with the EC is desirable. 
EC is falling behind in creating the standards required for the single market and constructing accompanying conformity assessment regime -- e.g., decision to postpone implementation of the EMC directive

-- European standards-setting bodies (CEN and CENELEC) haven't been able to generate standards rapidly enough to keep up with EC directives

- as a result, deadlines for implementing EC directives have been postponed

- conformity assessment procedures have not yet been implemented on an EC-wide basis

- member states continue to demonstrate a great reluctance to accept each other's notified bodies

Requirements that will prevail during this interim period remain to be determined

- EC must take steps to deal with the potential confusion in order to ensure that trade is not disrupted; and

- to prevent certain member states from using confusion as an excuse to impose/retain protectionist measures

U.S. exporters should be prepared for a period of uncertainty until single market directives are fully implemented 
U.S. and EC Commission have initiated and maintained a useful dialogue on standards, testing and certification issues

-- we plan to continue to use this dialogue to address the problems described above

We expect a Commission proposal on subcontracting soon

--We'll encourage the Commission and the Member states to provide for the maximum degree of flexibility in order to facilitate trade flows

Also expect the Commission to secure a mandate from the EC Council during the latter part of the year to begin negotiations on mutual recognition agreements

-- prior to that time, the U.S. government will need to decide whether to negotiate such agreements; and

-- if so, for which sectors and under what conditions

-- also need to weigh the alternatives, e.g., subcontracting, self-certification; and

- the interests of various U.S. industries

Finally, we must sort out the respective roles of the U.S. government and the private sector in this process 
VI. CONCLUSION

-- Issues before the workshop today are of great importance

-- We'll need your advice -- and that of other industries -- in order to make informed decisions on these issues

-- We look forward to working closely together in the coming months in order to address these issues satisfactorily 
Appendix C.3.

Remarks Before

Electromagnetic Compatibility Workshop

Sponsored by ACIL, AEA, \& NIST

April 4, 1991

\author{
Julius P. Knapp* \\ Deputy Chief \\ Authorization and Evaluation Division \\ office of Engineering and Technology
}

* The views expressed herein are solely those of the author and do not necessarily reflect the views of the FCC or members of its staff. 
The Federal Communications Commission is the U.S. Government agency responsible for regulating wire and radio communication used by the private sector. While today's workshop is intended to focus on how the U.S. Government can assist the U.S. electromagnetic compatibility community gain product acceptance within international markets such as the European Community, it is also important to understand the U.S. requirements and their relationship to the international commity. With that in mind I will briefly summarize the current FCC requirements for electromagnetic compatibility, their international ramifications, and some thoughts on current and possible future trends.

The FCC has established technical standards for radio and telephone equipment that, for simplicity, can be considered as falling into one of four general categories. The first category would be standards pertaining to transmitters used in authorized radio services such as broadcasting transmitters, cellular radios, and police, fire and other land mobile equipment. The second category would be standards governing low-power non-licensed transmitters such as door opener controls and cordless telephones. The third category consists of standards designed to limit the levels of radio noise generated and unintentionally enitted by electronic equipment such as personal computers and their peripherals. The fourth category would be standards to protect against harm to the public switched telephone network potentially caused by equipment such as telephone handsets and PBXs.

The FCC's technical standards are developed through rule making in accordance with the Administrative Procedure Act. Any interested party, whether foreign or domestic, can file comments on FCC proposed technical standards. To the 
extent possible and that which is appropriate, the FCC standards are consistent with international standards. This is particularly true for transmitters operating in the authorized services where the U.S. is obliged to establish standards consistent with the international radio regulations. There are several areas, however, where U.S. standards are currently at variance with internationally recognized standards. For example, the FCC radio noise limits for computer equipment preceded the development of international standards. As a result, the FCC standards differ from the international standards. Also, in some instances U.S. standards are more stringent in order to increase spectrum efficiency, such as in the domestic satellite service.

To ensure compliance with the various technical standards the FCC has established an equipment authorization program. There are several different equipment authorization processes that apply to the various types of equipment. Typically, the manufacturer is required to file a written application together with a measurement report showing compliance with the technical standards. The application is reviewed by the FCC staff and, assuming evervthing is in order, a grant of equipment authorization is issued within about 50 days of the filing date. Equipment may not be legally imported or marketed before the authorization is issued. An enforcement program is in place to ensure compliance and assess fines for violation of the rules. The FCC can elect to test a sample of the equipment to determine compliance either before or after authorization is granted.

Any party, foreign or domestic, may perform the compliance measurements submitted with the application for equiprent authorization. There is no 
requirement for laboratory accreditation. In essence, a laboratory performance determination is made each time an application is reviewed. If the measurement report does not document that the tests were performed properly, additional testing or a sample of the product may be requested.

There is one FCC requirement that is often misconstrued to be a laboratory accreditation progran. It is our requirernent for filing a test site description. Our rules for low power transmitters and radio noise control from electronic products rely heavily on measurement of field strength at an open-area test site. We require the submittal of an open-area test site description to ensure that the site can be expected to produce reliable measurements. In essence this is a one-time filing to avoid the need to submit this critical information with each application for equipment authorization. The information must be updated at least every three vears. Approximately 350 test site descriptions are on file with the FCC, about half of which are for foreign laboratories. This filing requirement is verv much different from an accreditation program in that no finding whatsoever is made as to the competence of the personnel to perform the measurements properly.

We are all keenly aware that the international landscape with regard to technical standards has been changing, driven in part by developments in the European Community. As Europe has moved to fill its needs for standards by 1992, the U.S. and other administrations have urged that international standards serve as the basis for EC 92 requirements. This, in turn has given increased importance and urgency to international standards development. At the same time issues such as testing, equipment certification, and laboratory accreditation have taken on global significance. 
Domestic forces are at work as well. Many U.S. manufacturers have urged that, where differences exist, the FCC should align its standards with international standards. There is also the persistent desire to improve the speed of the equipment authorization process. In addition, as a general observation, the staff of the FCC has found that the test data submitted by some laboratories is not consistently reliable. Thus, an on-going issue is how to improve this situation.

So, what might we foresee for the future. First, it seems likely that there will be increasing ermphasis on aligning FCC standards and measurement procedures for electromagnetic compatibility with those recognized internationally when it is in our interest to do so. For example, we already have an outstanding proposal to align U.S. measurement procedures for digital electronic equipment with international CISPR procedures. A proposal to conform the radio noise standards for such equipment with CISPR standards is anticipated later this year. Other IEC/CISPR standards are being considered as well.

There is likely to be further dialogue on whether laboratory accreditation or quality standards should somehow play a role in the FCC equipment authorization program. Certainly one concern is that, without such criteria, there would be a perception that the U.S. equipment authorization program tolerates poor-quality measurement work that is not of world-class caliber. This in turn could give rise to reluctance on the part of foreign bodies to accept measurement data from U.S. laboratories due to a perceived lack of 
adequate performance criteria. We are very much interested in the views of U.S. manufacturers and laboratories on this point.

It is unlikely the FCC will establish a separate laboratory accreditation or performance standards program. We simply do not have the resources. One possibility might be use of the National Institute of Standards and Technology's National Voluntary Laboratory Accreditation Program (NVLAP). It is also conceivable that the private sector could implement its own accreditation program for electromagnetic compatibility laboratories.

The question of mutual recognition agreements with regard to equipment authorization presents many complex technical, policy and legal issues. For instance, mutual recognition assumes equivalency of standards and measurement procedures. This is not currently the case for many types of equipment. Legal issues would include that of determining the party responsible for compliance and how to implement enforcement for parties without representatives in the United States. Although some potential exists for agreements with Canada, and there have been some verv preliminary discussions with Mexico, it does not appear that significant progress on these issues can be made in the near future on any sort of global scale.

In conclusion, the FCC is well aware that U.S. domestic requirements must also be considered from an international perspective. We are, and will continue to be, interested in how FCC requirements and policies affect the ability of the U.S. electromagnetic compatibility community to gain product acceptance within international markets. 


\section{Remarks of Judson C. French \\ Electromagnetic Compatibility Workshop \\ April 4, 1991}

I am from the Electronics and Electrical Engineering Laboratory at NIST, a technical lab based area of NIST. I want to tell you briefly what we do, or can do, which may be helpful to you - and indicate my role here which is oriented to technical support as opposed to policy development which has been treated by the previous speakers.

EEEL is devoted to measurement research and services that will provide new or improved measurement methods, or data, or calibration services, or SRMs, for the areas of industry that we support. In effect, we help make available the measurement tools that industry must have to provide and prove world leadership.

Our clientele includes the producers and users of electrical, electronic, and electromagnetic materials, components, instruments and systems.

Thus, we support the electronics industry and its customers broadly, as well as the other Federal agencies that depend on electronics.

The particular areas that we address are:

- Basic electrical standards (e.g., national standards for the volt, the ohm, and the ampere) on which all the rest depend

o Low frequency electronic instrumentation and the power community including the electrical utilities

o Fiber-optics and lasers, superconductors and magnetics

- Semiconductor materials, processes and devices

o r-f, microwave and millimeter signals, and

o most important to this meeting, electromagnetic interference or compatibility (EMC)/

Principally, in EMC we are concerned with the development of probes to measure EM fields accurately (examples include resistive dipoles, standard gain horns, and thermo-optic probes) and 
systems to produce well characterized fields (examples include TEM cells, reverberating chambers, standard radiators, open site facility, and anechoic chamber). There is other related research, for example, on methods to measure shielding effectiveness, emissions from devices and equipment, and immunity properties of connectors, cables, and large systems.

We publish the results of our work and offer training courses, and work with the voluntary standards organizations and in cooperative research and development activities to disseminate the results as effectively as we can.

We offer rather limited measurement services - special tests - to support where necessary the many commercial test houses which exist in this country and in this way provide traceability to NIST where it is required.

Thus, we do not offer regular formal calibration services, because we need make only a few, very diverse measurements in a year - typically only 10 or a dozen, leaving the regular measurements to the test houses.

We are working with the National Voluntary Laboratory Accreditation Program at NIST as they develop their EMC accreditation program and we are participating in international measurement comparisons to assure comparability of our measurements with other nations' central laboratories.

I should emphasize that we do not promulgate performance standards - though we give a lot of help to those who do.

And we do not develop products or processes except in those cases where they are needed for improved measurements and are not available commercially.

On the other hand, we do want to provide the central, generic, soundly evaluated technical backup which our industry needs in this area.

I am here because I want to hear what the industry wants to do itself, and what industry may want us to do at NIST for it in the technical area, in order for the industry to compete successfully in 
international markets as it is faced with new developments in the European community and with new international standards and international competition generally.

I hope what I learn can help our technical people prepare to assist you most effectively in the development of standards and accreditation procedures. 


\section{Appendix D}

Presentations by Private Sector Representatives 

Appendix D.1.

\section{OPENING STATEMENT NIST EHC/EC1992 WORRSHOP \\ APRIL 4, 1991 \\ THE POLICY ISSUE}

BY

WALTER A POGGI, PRESIDENT

RETLIF TESTING LABORATORIES

During my initial preparations for this presentation addressing the policy related issues of EC1992 and how it relates to the EMC community, I first decide to review Webster's definition of the word "policy". How interesting the review was since the definition is; policy - a course of action adopted esp. in state affairs, prudent procedure. Accordingly we can see that the definition addresses both the past tense "actions adopted" as well as current or future actions, "prudent procedures".

Is this not why we are here today, to review the "actions adopted" by the EC and to develop "prudent procedures" or positions to react to those actions. Since I believe that most if not all of you are quite aware of the mechanics of the European Community, I do not Eeel it necessary that at this forum we explore its inner workings in detail. Certainly it is suffice to say that:

(1) In general the Europeans have placed a greater emphases on testing and certification than we in the United States are traditionaliy accustom to.

(2) It would appear that under the present situation in the area of EMC and Telecommunications the openness of our FCC to foreign generated test data will not be mirrored by the EC.

(3) Assuming items one and two to be correct, the policy set forth by the EC can be one which will lead to control of their marketplace by testing and certification and may result at worst to trade barriers to U. S. manufacturers and at best to economic and logistic hardship to these manufacturers trying to penetrate the EC marketplace. And, 
(4) Such policies of either total or partial non acceptance of U. S. generated test data will have a devastating and paralyzing effect on the U.S. independent testing laboratory community who will be clearly be in a competitive disadvantage with their European counterparts.

Traditionally most if not all U.S. government run or overseen accreditation or listing systems freely accept foreign laboratories and their generated data. In our field this is quite clear. A review of the FCC listing program will show that the program currently lists 76 foreign laboratories 16 of which are European. Other examples of this openness, both within and outside of the EMC area, are the NVLAP programs, OSHA NRTL program and the now developing Fastener program.

One argument which many of us have heard from the EC is that "their not quite sure how to accredit U.S. Laboratories. There are models! Many of us in the independent testing community and I would think several captive manufacturer laboratories, have been accredited by the Canadian Dept. of Communications for Telecommunications testing. The program is clear, concise and successful, providing U.S. telecommunication manufacturers equal access and treatment to the Canadian marketplace as Canadian manufacturers are offered to our marketplace.

Another policy position which the EC has seemed to embrace is one of "subcontracting". Their position being, "We do not have to provide you with "Notified Body Status" since you may be allowed to provide the same testing services through a subcontracting basis with an European laboratory who is a notified body. What we must 
ask ourselves here is do we want that type of control of our testing and certification community in the hands of the Europeans. Who will the Europeans subcontract with? All qualified U.S. laboratories or only the few that they feel will be of benefit to them. I tend to believe that latter which can clearly result in a restraint of trade within the U.S. testing community and potentially clear discrimination against small business, i.e. small laboratories in this country. All while their 16 FCC listed laboratories still exploit the openness of the U.S. marketplace.

Clearly based on the latest EC document covering "subcontracting", it appears that the $E C$ is more interested in the economic implications of subcontracting rather than the technical. To give an excellent example of this mentality I only have to sight a the recent conversation my Quality Assurance Manager recently had with a B.S.I. representative after he recently completed a B.S.I. training program on registration of quality systems. When asked by my Q.A. Manager how RETLIF could enter into a subcontracting agreement with B.S.I., the B.S.I. representative's Eirst question was "How big is RETLIF?"

Is the EC "dragging its feet"? Are they attempting to "stonewall" progress? Yes! Yes! Yes! All one has to do is review their documents, their positions, their studies. The recent "subcontracting" document is a perfect example. Did they put together a position paper on the matter? Yes. Is it Reasonable? No. Is it workable? No. The time for action is now, the time for a clear message is now. We can begin by setting forth clear and unified positions from this workshop. The challenge is ours, now let's meet it. 
Position paper on the European Community (EC) 92 Conformity Assessment Issues - some Economic Factors about the Electromagnetic Compatibility (EMC) sector

Presented at the 4 April 1991 workshop - Held at the U.S. Department of Commerce (DoC) and co-sponsored by American Council of Independent Laboratories (ACIL), the American Electronics Association (AEA), and the DoC National

Institute of Science and Technology (NIST).

\section{April 1991}

James Wm Johnson

Amador Corporation

Taylors Falls, Minnesota 55084

\section{Introduction}

Jim Johnson, Associate and CEO of Amador Corporation, is the American Electronics Association (AEA) Minnesota Council Chair and "Issue Manager" for Conformity Assessment Issues, and a member of American Council of Independent Laboratories (ACIL). He has been involved for a number of years in discussions with the Europeans relative to standards and testing and certification i.e., the heads of the European Committee for Standardization (CEN), the European Committee for Electrotechnical

Standardization (CENELEC), the European Organization for Testing and Certification (EOTC) and the Commission of the European Communities (CEC). These remarks represent the position of Amador Corporation and do not necessarily represent any organization to which either Jim Johnson or Amador belong.

\section{Executive summary}

1 There is a structural and historical change occurring in contemporary politics. This change is best illustrated by the emergence of the European Community (EC). The EC, the world's largest market, will begin on January 1, 1993. That market is dominated by the European Parliament whose largest single faction is socialist Party with whom consumer protection and environmental protection are very important. This change is not only affecting our common life but also the realities of the testing and certification community of the U.S. of which Amador is a member.

2 Conformity assessment is a "technology policy" issue. The Washington, DC-based Computer Systems Policy Project (CSPP), in their 26 February Report entitled: "Perspectives on U.S. Technology Policy, Part II: Increasing Industry Involvement," calls for improving the U.S. technology policy and concluded the report by saying (in part): 
"Improving U.S. technology policy requires a long-term commitment and a series of changes by industry and government over time." (Emphasis added.)

President Bush who, in his recent (January 1991) State of the Union address called for renewed efforts to encourage R\&D, promote exports, open up foreign markets, and enhance American competitiveness overseas. Fundamental to accomplishing the President's aims is the improvement of a U.S. technology policy, which would include the matters of standards and conformity-assessment.

The U.S. economy is inextricably interlinked with Europe and Japan, and so while the General Agreement on Tariffs and Trade (GATT) and specifically the Agreement on Technical Barriers to Trade (GATT Standards Code) are languishing, the U.S.'s bilateral negotiations on conformity assessment with the EC hold special meaning.

Like it or not, the activities of the EC are shaping our economy and our conformity assessment practices. The U.S. is no longer autonomous from the global system. We are fundamentally interlinked with the EC. And the EC is not happy with the U.S. Government (USG) trade barriers. In the E.C.'S report on U.S. Trade Barriers, you note the use of terms such as "unreasonable," "lukewarm U.S. participation in international standards-setting," and so on. The power of the EC to influence change in the U.S. cannot be underestimated, particularly in its influence on the ability for U.S. manufacturers of electronic equipment to export to the EC.

a The Europeans are adamant about American government participation in conformity assessment (including EMC) in order to reflect a mutual EC/U.S. quality in the testing and certification of products.

b U.S.-based labs should have to qualify to become a notified body.

c The Department of Commerce (DoC) National Institute of Science and Technology (NIST) National Voluntary Lab Accreditation Program (NVLAP) is a sufficient qualification.

d A genuine dilemma for our nation's politicians has been created. The status quo is no longer an alternative.

The USG, in the body of the Federal Communications Commission, must become more regulatory with a vision, muscle, and an overwhelming desire to improve quality to enable U.S. electronic firms and its EMC testing labs to be 
world-class. The only answer for the U.S. is to change. And we can change! William James said it best:

"Not a victory is gained, not a deed of faithfulness is done, except upon a maybe; not a service, not a sally of generosity, not a scientific exploration or experiment or textbook, that may not be a mistake. It is only by risking our persons from one hour to another that we live at all. And often enough our faith beforehand in an uncertified result is the only thing that makes the result come true."

a The FCC must make a commitment to change. We must also come to understand change and, as James says, we must be willing to make "mistakes" in developing our strategies.

b Today's NIST workshop is the forum to introduce and discuss change in the EMC conformity assessment sector. And so we must understand the EC and its position.

c The Secretary of the Doc must change and aggressively adopt a position of encouraging increased USG oversight in areas of conformity assessment.

d Specific change of strategy and tactics is called for on the part of the FCC. We encourage the adoption of this position to be used by the USG as a negotiating basis with the EC.

e Amador feels that this overall position of greater government oversight is consistent with the positions recently adopted by some trade associations in particular in calling for a USG response to Japan and the U.S. reaction to Japan's competitiveness.

$f$ Conformity assessment relates to electromagnetic compatibility (EMC). Without a globally significant change to U.S. standardization and conformityassessment, the U.S.'s technologically-based economy alternatives are virtually non-existent in today's economy.

9 The USG, as a matter of public policy, must to react to the EC's position in the area of standardization and conformity-assessment by a reexamination of the traditional U.S. attitudes and by making a commitment to adopt a technology policy in these matters.

h This position proffered is consistent with certain Washington, DC-based trade associations, particularly in the health care and mechanical engineering fields. 
7 "Subcontracting" can only be considered an avenue for potential discrimination with resultant impact on U.S. electronic firms and U.S. testing and certification bodies.

8 It is Amador's sense that the 'CE' mark of conformity is going to become so generic that its acceptance (by itself) as a genuine quality mark either in the EC or the U.S. is debatable.

9 Amador believes that the product liability implications of the EC directives, including the EMC directive, have not been given full consideration by U.S. and EC manufacturers.

10 The EMC recognizable mark of conformity for EMC today is the Radio Protection Mark of the VDE Prüf- und

Zertifizierungsinstitut -- VDE Prüfstelle of the Verband Deutscher Elektrotechniker (VDE) of Germany. This mark could and should serve as an international mark for EMC conformity for emissions.

11 The need for a U.S. conformity assessment mark is currently being resolved by a private initiative through some members of ACIL.

12 The USG should indicate to the EC its willingness to accept the GATT proposed "Code of Good Practice."

\section{Background - The U.s. Negotiating Position}

The U.S.'s negotiating position relative to the European's is slipping relative to the rest of the world. The reason is the emergence of the democracy and subsequent capitalism of Eastern and Central European countries and their interest in becoming one with and/or working with the EC. The U.S. has always been in second position to the EFTA (the non-EC countries of Europe: Norway, Switzerland, Austria, etc). in matters of mutual recognition, etc. The EC/EFTA relationship in the conformityassessment area, has been more fully solidified over the last months. The U.S. progress in these matters, by comparison to the EFTA effort, seems to be insignificant.

Defining the issues dealing with standards and conformity assessment may be compared to "viewing" a person's individual health where, one works with a "standard" that is universal, easily defined and recognizable - the standard of a "healthy" body. One measures, or provides a "standard" on just how healthy a body actually is. Universally accepted, international standards are equally recognizable.

High-technology products require standards and subsequent conformity assessment. Standards need to be enforced in a manner that lends itself to equity by all participants. Standards are 
equivalent to quality in the product. standards are quality. The testing and certifying to standards, thus is at the core of technology today and throughout the world.

\section{EMC standards}

Juxtapose the world-wide cry for standards and quality with the following actions of the FCC as reflected in the 16-17 January meeting of American National standards Institute (ANSI) Accredited standards Committee on EMC (C63):

"Art Wall (of the FCC) expanded on the issue (i.e., general concepts in development of industry EMC standards presented in a letter from the FCC to C63) by pointing out that the Commission is interested in the possibility of reducing the burden on industry to obtaining interference control. The Commission could encourage innovation by using potential relaxations of regulatory requirements as an incentive, without restricting design, while adding more general aspects."

While Amador makes no argument for "reducing the burden on industry," we rush to make the point that from our perspective, the FCC can best reduce the "burden" by adopting an international standard. And while "innovation" in EMC practices and R\&D is laudatory, calling for an even greater "relaxations of regulatory requirements" is antithetical with the rest of the world's strong interest to protect the spectrum. This is precisely the signal that the FCC and the USG is sending the EC on EMC.

While this paper is confined to "economic issues," one cannot separate the "technical" aspects of the FCC EMC standards from the economic issue. In a word, multiple testing to multiple EMC standards is expensive. Appendix A illustrates the comparison of the FCC with the VDE and the European Norm (EN) 55022, the EC version of IEC's International special Committee on Radio Interference (CISPR) 22.

Note that virtually everything is different from the definitions to the conducted emission set-up and most importantly, the FCC's insistence on maintaining a 3-meter horizontal antenna distance for the Class 8 Equipment Under Test (EUT). The FCC's argument is that the "FCC-Iisted" labs (the FCC goes to an extreme effort to not let anyone think they "accredit" and/or certify lab sites) have made an investment in 3-meter sites and that they are wary to change the specification. In other words, they give an economic argument for the perceived lower standard.

This failure to adopt the 10-meter EUT-to-horizontal-antenna distance has proven to be expensive for U.S. manufacturers.

The following is an example of a major U.S. PC manufacturer who 
designed a PC to meet the 3-meter standard.

When the PC was retested at 10-meters for VDE, it failed and had to be redesigned with the subsequent loss of German market introduction.

If the FCC would adopted CISPR 22 like virtually everyone else has, except Canada, U.S. firms could save considerable money performing EMC testing and shorten the time-to-market.

Today's new global imperatives, with the emergence of EC, specifically in the areas of technology, give us an environment in which United States companies are having to adapt. In the German and Japanese economies you find an almost exclusive adoption of international standards, usually government-driven standards. The organization that coordinates these global standards for electronic firms is the International Electrotechnical Commission (IEC).

The IEC is the equivalent to the Iso except that it deals with electrical equipment. IEC is an organization that consists of 43 countries including the United states. As a point of reference, these countries account for $95 \%$ of the world's energy production.

The IEC's theme is to adopt and promote world-wide standards. of the literally tens of thousands of standards that the IEC has developed, we in the United states have adopted a mere handful. We participate in the standards-setting, but we do not adopt the standards. This hurts our exporters. And in today's economic environment, especially with the "cheap" dollar, exports have to be a major player in any manufacturer's product mix. On the other hand, the regional standards body for electrical equipment in Europe, CENELEC, takes great pride in noting that of its one thousand standards, $85 \%$ reflect IEC!

We have a unique situation within the U.S. Where designing equipment is typically done to meet standards which are internal, internal-to-the U.S., internal-to-a-manufacturer. That is, standards have been developed relative to the particular operation or company that is manufacturing the product, not through government involvement (except in the area of health care and safety).

\section{EMC Immunity standards}

Companies such as IBM, Control Data, Unisys, etc. for the most part have a strongly developed catalog of internally generated immunity (susceptibility) standards. There are no U.S. regulated immunity standards. With the adoption of the EC EMC Directive, U.S. firms must conform to the EC Directive. 
U.S. internally-generated standards are not developed in a vacuum. Companies send their people to voluntary standards organizations, mostly in conjunction with the sector-

administrated ANSI. A de facto "nationalization" of standards then occurs through this somewhat informal process. Thus we have had a "nationalization" of standards, but without government oversight.

It is argued that producing standards and operating U.S. companies in this fashion has been adequate (for the U.S.) in the past. So in the jargon of some in United States today: "If it ain't broke, don't fix it." The EC doesn't see it that way.

In a recent report by the CEC under the section entitled: "STANDARDS, TESTING, LABELLING AND CERTIFICATION," it reads in part:

"In general, there is a continuing concern in the EC with regard to the standardization process in the United states. Whereas the European Community is fully committed to the implementation of international standards as a way of ensuring open access to markets, the United states still appears to place more emphasis on non-standard solutions.

According to the US sources, as of 1989, out of 89,000 standards used in the US, only 17 are directly adopted from ISo (International organization for standards) standards. No IEC (International Electrotechnical Commission) standards have been adopted. The Federal Government refers to about half of these standards in its technical regulations, thereby making them mandatory. This situation is difficult to reconcile with the GATT Standards code. Under this GATT Agreement the US Federal government is obliged to use International standards as a basis for its own technical legislation and therefore not to use US standards which deviate from International standards. The US Federal government is also obliged to take such reasonable measures as may be available to it to ensure that private standardizing bodies and states use international standards. None of this seems to happen in practice.

This situation represents a fundamental problem for EC companies wishing to sell in the US market. They often have to produce a separate product for the US market, thus incurring extra costs unnecessarily and reducing their competitiveness.

Problems for potential EC exporters are further increased by the lack of any central standardizing body covering the entire US territory, as exists in the community and in other countries such as Canada. In the US, there are more than 600 private organizations engaged in standardizing 
activities. There is no guarantee that by following one particular standard a product will be accepted throughout the US, the more so as states and other local government bodies often have additional legal requirements of their own. A similar situation exists for testing and certification requirements.

If one adds to this the fact that there is no central source of information on the entire range of standards and conformity assessment procedures, and the fact that the US has a very strict product liability system, it is easy to see that exporting to the US can be a major headache, especially for small and medium enterprises."

The EC say they have a problem.

The U.S. standards community itself consists of companies and professionals, and trade associations, the "sector" portion of the infrastructure.

\section{The EC's Approach}

The CEC is calling for more global government involvement. The EC sees the need to deliver a "world-class" quality product and international standards are emphasized. For the EC, this government initiative is noted in the "Green Paper" produced by the CEC. Gordon Gaddes from CENELEC,' has summarized, in part, this document, and I quote:

"standardization is recognized to be pivotal to Community policies

a central (to the EC), authoritative, coordinating standards body is desirable"

The Europeans have developed a novel approach, an approach we should study - the European organization for Testing and Certification (EOTC) - which they call "A New Partnership." CEC representatives pointed out to Jim Johnson that the EOTC initiative was something that they (CEC) "got no choice" but to accept. The EOTC has a new approach to the public/private sector interaction. A true partnership, that combines the best of the private and public sectors. While we should not necessarily mimic the EOTC, there is a genuine need for the U.S. to be more creative in its approach. The EOTC has been called a program with vision.

1 See Simons Inaugural Lecture: "European Standards opportunity or Threat" given to the ISA International society, October, 1990. 
The Europeans will get their "Europeans Standards Organization" and U.S. companies will be at a competitive disadvantage.

In the EC, the process consists of the various governments (Members) and others who have committed themselves to direct participation in the standards system they call these Agreement Groups.

In the U.S., the process is driven by corporations. It is not driven by the USG except in very specific areas of health and safety.

\section{EMC Conformity Assessment}

Even stronger signals are being sent to the EC in the conformity assessment area. Conformity assessment is the determination of the ability of a product to be compliant with the rules and regulations of a national authority or national body such as the USG, the EC, etc. Another definition, this time from ISO ... Conformity: "Fulfillment by a product, process, or service of all requirements specified."

Thus, conformity assessment is the process of determining if a product does in fact fulfill the requirements. The process includes testing. (the interest of the Amador Corporation) certification, quality assurance, quality systems registration and laboratory accreditation.

\section{The FCC and Conformity Assessment}

The most galling of all of the cries of "Fortress Europe" are those that relate to the issue of FCC-listed labs and the existence of the National Institute of Science and Technology (NIST) National Voluntary Lab Accreditation Program (NVLAP).

The sense of the frustration of the industry about the inability for the FCC and the DoC to get together in the issue has been well documented by the U.S. General Accounting office (GAO) in a well-circulated and systematically ignored report and recommendation.

The EC is quite aware of this. The signal ANSI's C63 committee recently (17-January-1991) sent to the EC was the following motion:

"the C63 Ad Hoc Committee on International Accreditation of EMC Measurement Facilities wrote a letter to (NIST's) Dr. (Stanley) Warshaw (the Director of the office of standards Services) to ask him to start procedure for accrediting EMC labs under the present (NVLAP) procedure for European requirements." 
The signal to the EC that should be sent is:

That USG has a formal EMC lab accreditation program accepted by the USG under DoC in which all EMC labs testing to EMC standards must comply by.

Anything less is an indication of the level of quality that the USG is willing to live with. And the EC knows it.

\section{Kaintaining the status Quo - A Prescription for Disaster}

The future competitiveness of U.S. firms is being threatened by major forces who have a vested interest in maintaining the status quo. There are some who do not feel that maintaining the status quo is the best for the U.S. Mike Miller of AAMI is one of these. In October, 1990, Mike Miller and Jim Johnson were part of the U.S. delegation to the most previous meeting held in

Brussels with representatives of the private standards operations and the government operations of the European Community. Our delegation, which was sponsored by ANSI consisted of approximately 16 people representing industries such as the health industries, manufacturers, the National Electrical Manufacturers Association (NEMA), and other manufacturers. The April meeting's attendance will be similarly constructed.

Jim Johnson continuously perceived a fundamental problem in Brussels, a structural problem in the biases of the majority of the U.S. delegation. The majority (the ones who had the most to lose) are those who want to maintain the status quo.

\section{A Case Study - Medical Electronic Devices}

In Germany, medical electronic devices are constructed and designed with critical elements relative to voltages (leakage currents) and electromagnetic compatibility (EMC). If a U.S. firm wishes to export to the FRG, the product may be brought to an EMC lab for testing. Tests of a preliminary nature are performed on the equipment, and it is then determined if the product is compliant to the German rules.

Amador Corporation's experience is that generally the U.S. product fails this preliminary test. The result is a more extensive and expensive re-work of the equipment's design to ensure EMC compliance to the rules of the FRG Verband Deutscher Elektrotechniker (VDE). This process is now required in order to bring the product into compliance with the laws of Germany. Typically the engineering department would determine that such a re-design would take perhaps 6 months which would make the firm lose the product's "window of opportunity" to penetrate a fastchanging market, and, thus, be unable to market in Germany. 
When the product was originally designed, the international aspects of compliance to product safety and electromagnetic compatibility could have been very easily and at a relatively modest cost been designed into the product. The product itself could have been a product accepted throughout the globe.

\section{Medical Blectronics Firms Understand Conformity Assessment}

In reality, the larger manufacturexs in the medical industry are really the most "in tune" relative to other industry sectors with what is happening in the European community and it is the smaller firms who are penalized for not anticipating the requirements for participating in a global market.

Mike Miller, who was a member in the U.S.-ANSI sponsored delegation to the EC in october, was recently quoted as saying that the EC's "new approach" to standards, testing and certification raises a "greater need for unity between the voluntary sector and the government." Mike Miller is the U.S.based executive director of the Association for the Advancement of Medical Instrumentation (AAMI) and calls the environmental change in standards we observed in Brussels "a new order." And, as reported in Laboratory Regulation News, ${ }^{2}$ he says that the strict separation in the united states of the voluntary standards organizations and the federal government is "outdated." He says that policies of "isolation and going it alone can't work." He feels that the United states must act with a "single purpose."

The medical electronics community, in cooperation with the FDA, has limited itself to merely setting up a "voluntary" program, a program that now is being recognized as greatly limiting our ability as a nation of producers of medical electronic equipment to compete worldwide. Mike says "isolation ... cannot work." Jim Johnson could not agree more.

\section{GATT and the Issue of EMC standards and conformity Assessment}

General Agreement on Tariffs and Trades (GATT), the Uruguay Round of those talks, are scheduled to be continued. GATT talks are intrinsic to the content of the upcoming EC/U.S. discussions. The Europeans state that access by the U.S. manufacturers to the European markets is "enshrined;" however, the CEC does not seem to be willing to compromise in many areas which, by definition, would preclude access of our products to the EC market. This lack of access would be based upon conformity-assessment issues.

2 Laboratory Regulation News, Volume 1, Number 18 
The Europeans are stating unequivocally that the major requirement for access by AEA's members to the EC markets is U.S. government oversight in the areas of conformity-assessment. The major area to be discussed will be the perception of both CEN/CENELEC and the CEC of the willingness of the U.S. to have a Federal Government "oversight" role in matters of conformity assessment. They note our positions in the GATT talks. Here it is particularly apparent in the positions taken by the U.S. in areas of the proposed GATT "Code of Good Practice of the Preparation, Adoption and Application of Standards": accreditation systems and certification schemes.

Another indication of the willingness of the CEC to generate "debate" in these matters is the production of the CEC's "Green Paper." The paper is entitled "Commission Green Paper on the Development of European Standardization: Action for Technological Integration in Europe." The title alone tells the story. One could say:

\section{"The 0.8. must adopt international standards and international conformity assessment or die."}

It is obvious that the EC has the IEC/ISO standards generation and adoption system wired. The Europeans control almost $90 \%$ of the secretariats of IEC. The U.S. has only one choice, adopt international standards. Or in the words of the title of an article in the latest issue of Evaluation Engineering, "International Compliance: Conform or Perish?"

\section{A Machiavellian Thought}

Consider this Machiavellian thought that the Europeans are betting that the U.S. will not back down on the CEC requirement for U.S. government oversight of conformity assessment matters and "Fortress Europe" will be the de facto result.

And they can play tough. Our U.S. electronics sector got a clear message as reported by the 27-March-1991 Wall street Journal:

"Though the commission proposals include free-market rhetoric, the separate (expelling non-EC competitors) announcement indicates how strongly key industry players are pushing for government help what they call unfair competition by Japanese and U.S. rivals."

\section{summary and conclusion}

The U.S. has been backward (in the eyes of the EC) on standardization and conformity assessment issues. 
The CEC has pointed out how their attitude about these issues as held by the EC, and the EFTA countries, puts these countries and their manufacturers at a distinct advantage to those of the U.S.

The inability of the USG to move off the position of no government oversight is pivotal to any successful U.S./EC negotiations.

The FCC is challenged to respond to the notion that change is required for U.S. to compete globally. And they are standing in the way of that change!

As noted by AAMI's Mike Miller, there is a public/private partnership in the EC. We need such partnership the U.S. Indeed, we have no genuine U.S. technology, no U.S. competitivepolicy. We have no policy except "let the marketplace decide." In the areas of standardization and conformity-assessment, that "will not wash" with the CEC.

The theories of classical economics of laissez-faire; let's let the marketplace determine whether or not someone will purchase the product, should be over in the U.S. when it comes to hightechnology products. It is in the EC.

If we are to work with the EC, we have to recognize some simple facts. These remarks were given by Bert van Barlingen of the CEC DG III A 1. He offered the following syllogism:

"a) Private standards can be a barrier

b) Governments should be concerned

c) Governments deal with Governments

d) Governments should deal with its own private sector."

Please FCC; please DoC; "deal with (your) private sector." The USG and, indeed, all U.S. industry should listen to Mr van Barlingen and the others in the EC. We should listen and hear about what they feel are the public policy issues in conformity assessment. If we do not, the U.S., as an exporting nation, is going to have some major problems. And calling these problems "Fortress Europe" is an insult to our European colleagues who, I believe, are (for the most part) trying to work through these difficulties with us.

Some in American industry are very strong and well organized to try to move their agenda. But just as the Generals of the Armies are wont to fight the war-of-the-day with the battle plans appropriate for the last war's campaign, many seem to be excessively burdened by its long held anti-government positions which have been espoused throughout the $80^{\prime} \mathrm{s}$.

While it may not seem initially very popular to call for a change, a new 0.s. government/corporation partnership, a 
public/private partnership, the USG is handicapping its members by not encouraging global participation in the standards and conformity-assessment processes.

Senator Hollings says: "We are the government." And so the dilemma. It is claimed that Americans are paranoid about the possibility of governmental oversight.

And so here again is Jim Johnson's Machiavellian nightmare. This perceived paranoia may in fact be the linchpin of the artificial trade barriers of EC 92, the so called "Fortress Europe." This paranoia on the part of some of our nation's manufacturers is well known by the CEC and others in the European Community. This paranoia may in fact become the single biggest reason that American firms will be kept out of the European Community extensive markets. NIST and the FCC can make the difference.

\section{Background on Amador Corporation}

Jim Johnson is an co-owner (with Dan Hoolihan) of a small Electromagnetic Compatibility (EMC) business heavily involved in the areas of European testing and certification primarily in conjunction with the Federal Republic of Germany (FRG) Verband Deutscher Elektrotechniker (VDE). Along with his responsibilities with AEA, Johnson is the ACIL EMC and Telecommunications Issues Chair, the Chair-elect of the Minnesota High Technology Council (MHTC), a member of the U.S. Department of Commerce (DOC) and U.S. Office of the United States Trade Representative (USTR) Industry Functional Advisory Committee on Standards for Trade Policy Matters (IFAC 2), the International Electrotechnical Commission (IEC) International special Committee on Radio Interference (CISPR) CISPR Subcommittee B: Interference from Industrial, Scientific and Medical Radio Frequency Apparatus (CISPR/B) Technical Advisory Group (TAG), a member of ANSI's Z34 Certification Committee and an alternate member of $\mathrm{C} 63$ Accredited standards Committee on EMC (C63).

Amador Corporation is a conformity assessment firm and a spin-off from Control Data Corporation. They are developers and producers of software for EMC and a testing and certification firm for EMC for electronic devices, particularly Information Technology Equipment (ITE). Since 1984, they have expanded in Minnesota into New Brighton, just north of St. Paul where they perform tests on pacemakers and military equipment to standards of the U.S. Federal Government. Within the last two years have built a facility near IBM-Rochester on the Zumbro River in Minnesota. Amador Corporation has constructed a new facility just north of Boulder, Colorado and still another laboratory south of stuttgart, Germany. They also have a 50:50 joint venture in the Soviet Union. 
$\Lambda$

$\mathrm{M}$

A

$\mathrm{D}$

$\Theta$

$\mathrm{R}$

\section{A COMPARISON OF FCC, VDE AND EN 55022 REGULATIONS}

\begin{tabular}{||c|c|c|c||}
\hline SCOPE & U.S. FCC & GERMAN VDE & CISPR 22 \\
\hline Definitions & $\begin{array}{l}\text { Computing } \\
\text { Devices }\end{array}$ & $\begin{array}{l}\text { Electronic } \\
\text { Data } \\
\text { Processing } \\
\text { (EDP) }\end{array}$ & $\begin{array}{l}\text { Information } \\
\text { Technology } \\
\text { Equipment } \\
\text { (ITE) }\end{array}$ \\
\hline
\end{tabular}

\begin{tabular}{|c|c|c|c|}
\hline $\begin{array}{l}\text { MARKETING } \\
\text { RESTRICTIONS }\end{array}$ & U.S. FCC. & GERMAN VDE & CISPR 22 \\
\hline Class A & $\begin{array}{l}\text { May be sold } \\
\text { only to } \\
\text { non-residential } \\
\text { users }\end{array}$ & None & Optional \\
\hline Class B & None & None & None \\
\hline Class C & $\mathrm{N} / \mathrm{A}$ & $\begin{array}{l}\text { Licensed } \\
\text { for } \\
\text { approved } \\
\text { site }\end{array}$ & $\mathrm{N} / \mathrm{A}$ \\
\hline
\end{tabular}




\section{A COMPARISON OF FCC, VDE AND EN 55022 REGULATIONS}

\begin{tabular}{|c|c|c|c|}
\hline TECHNICAL & $\mathrm{U} \cdot \mathrm{S} \cdot \mathrm{FCC}$ & GERMAN VDE & CISPR 22 \\
\hline $\begin{array}{l}\text { Horizontal } \\
\text { Antenna } \\
\text { Distance (m) } \\
\text { Class A } \\
\text { Class B }\end{array}$ & $\begin{array}{c}3 \text { or } 10 \\
3\end{array}$ & $\begin{array}{c}10 \text { or } 30 \\
100 \text { (H-Field) } \\
10 \\
3 \text { or } 30 \text { (H) }\end{array}$ & $\begin{array}{c}3,10 \text { or } 30 \\
3 \text { or } 10\end{array}$ \\
\hline $\begin{array}{l}\text { Vertical } \\
\text { Antenna } \\
\text { Height (m) } \\
\text { Class A } \\
\text { class B }\end{array}$ & $\begin{array}{l}1-4 \\
1-4\end{array}$ & $\begin{array}{l}1-4 \\
1-4\end{array}$ & $\begin{array}{l}1-4 \\
1-4\end{array}$ \\
\hline $\begin{array}{l}\text { Conducted } \\
\text { Emission } \\
\text { Test Setup } \\
\text { (Table-top) }\end{array}$ & $\begin{array}{l}0.8 \text { meter } \\
\text { above ground } \\
\text { plane (floor) } \\
\text { and back of } \\
\text { EUT } 2 \text { meters } \\
\text { from wall, } \\
\text { sides } 1 \text { meter } \\
\text { min distance } \\
\text { to walls }\end{array}$ & $\begin{array}{l}0.8 \text { meter } \\
\text { above ground } \\
\text { plane (floor) } \\
\text { and back of } \\
\text { EUT } 0.4 \text { meter } \\
\text { from wall, } \\
0.8 \text { meter } \\
\text { from LISN and } \\
\text { other metal } \\
\text { surfaces }\end{array}$ & $\begin{array}{l}0.8 \text { meter } \\
\text { above ground } \\
\text { plane (floor) } \\
\text { and back of } \\
\text { EUT } 0.4 \text { meter } \\
\text { from wall, } \\
0.8 \text { meter } \\
\text { from IISN and } \\
\text { other metal } \\
\text { surfaces }\end{array}$ \\
\hline $\begin{array}{l}\text { Cable } \\
\text { Termination }\end{array}$ & $\begin{array}{l}\text { One of each } \\
\text { type of } \\
\text { peripheral } \\
\text { must be } \\
\text { connected to } \\
\text { the system * }\end{array}$ & $\begin{array}{l}\text { Each cable } \\
\text { port must } \\
\text { have a cable } \\
\text { attached to } \\
\text { it }\end{array}$ & $\begin{array}{l}\text { One of each } \\
\text { type of } \\
\text { peripheral } \\
\text { must be } \\
\text { connected to } \\
\text { the system * }\end{array}$ \\
\hline \multicolumn{4}{|c|}{$\begin{array}{l}\text { * - The standard has it worded, so that using one is } \\
\text { sufficient "provided it can be shown that the additional } \\
\text { cables would not significantly affect the results." }\end{array}$} \\
\hline
\end{tabular}




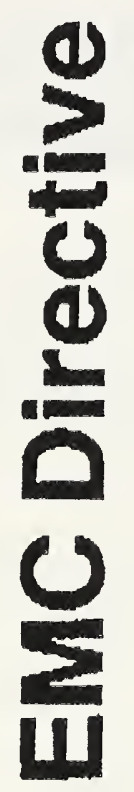

$\frac{1}{5}$
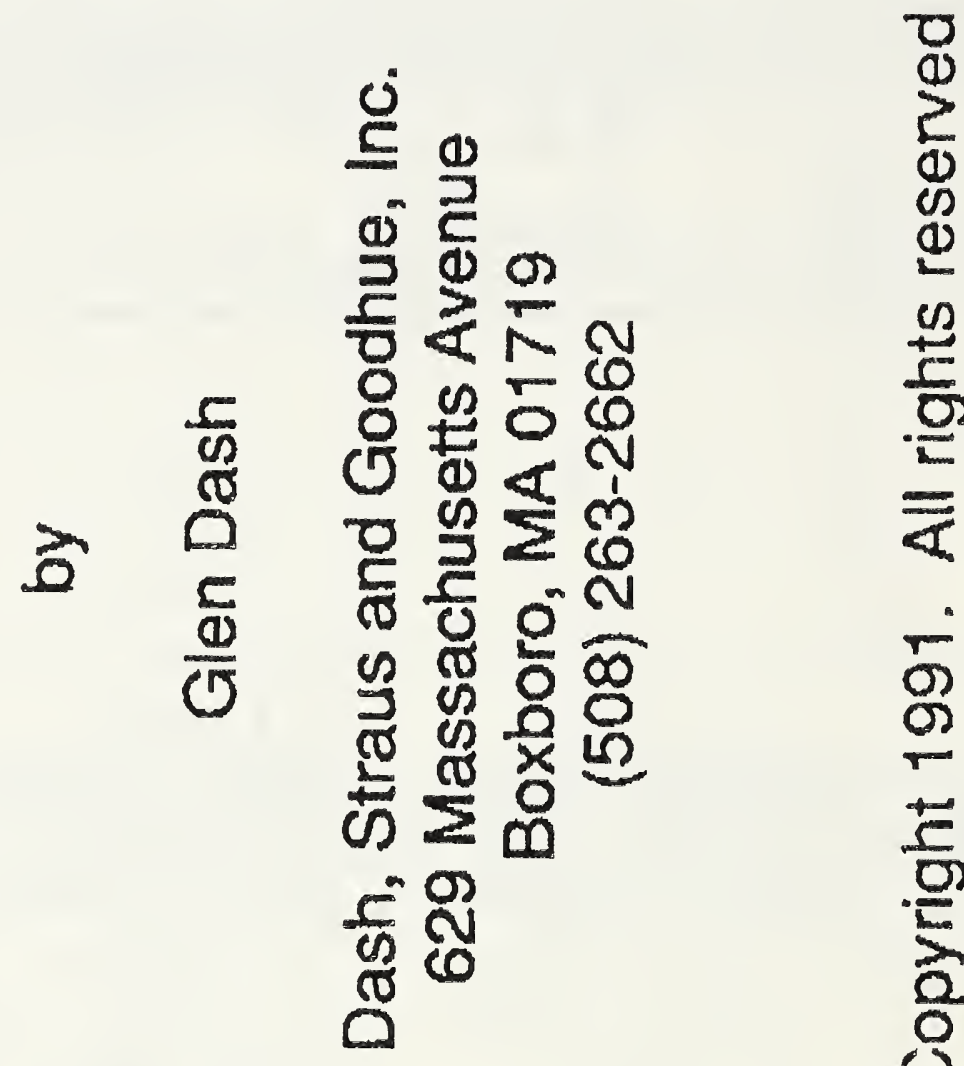

ᄃี ญ

$\frac{1}{0}$

$\frac{5}{8}$
$\frac{0}{5}$
$\frac{5}{2}$
$\frac{0}{8}$ 


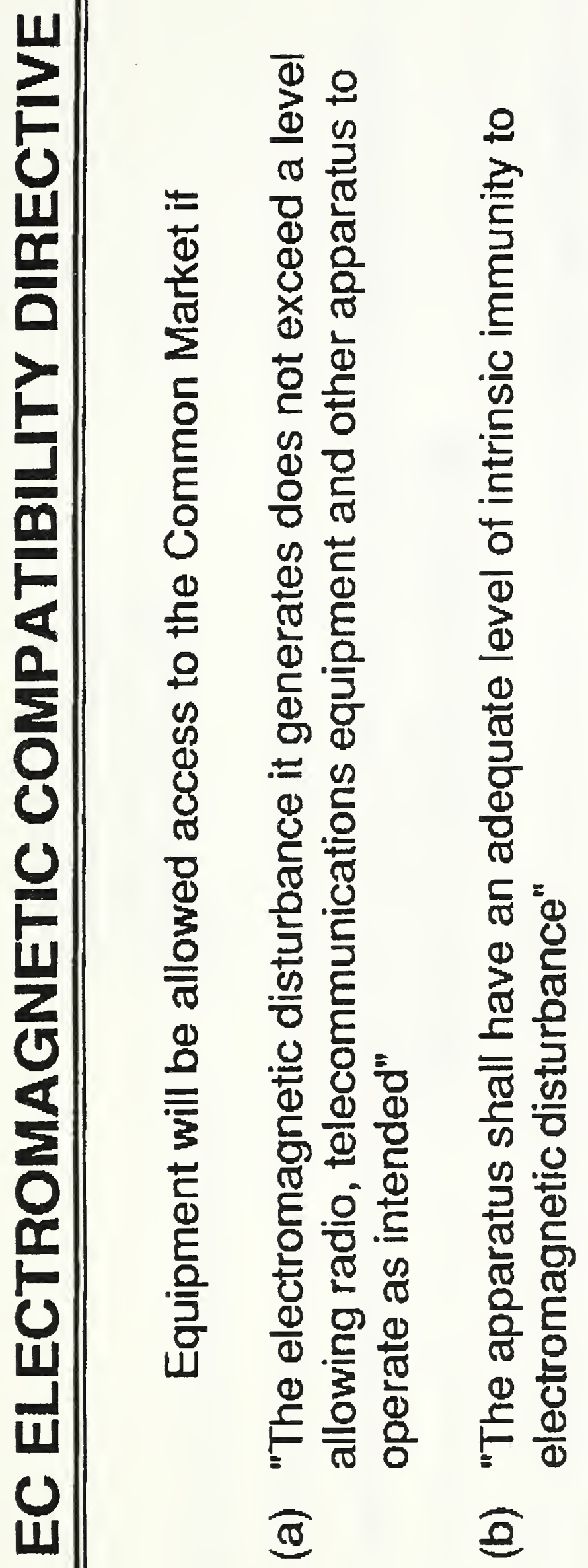




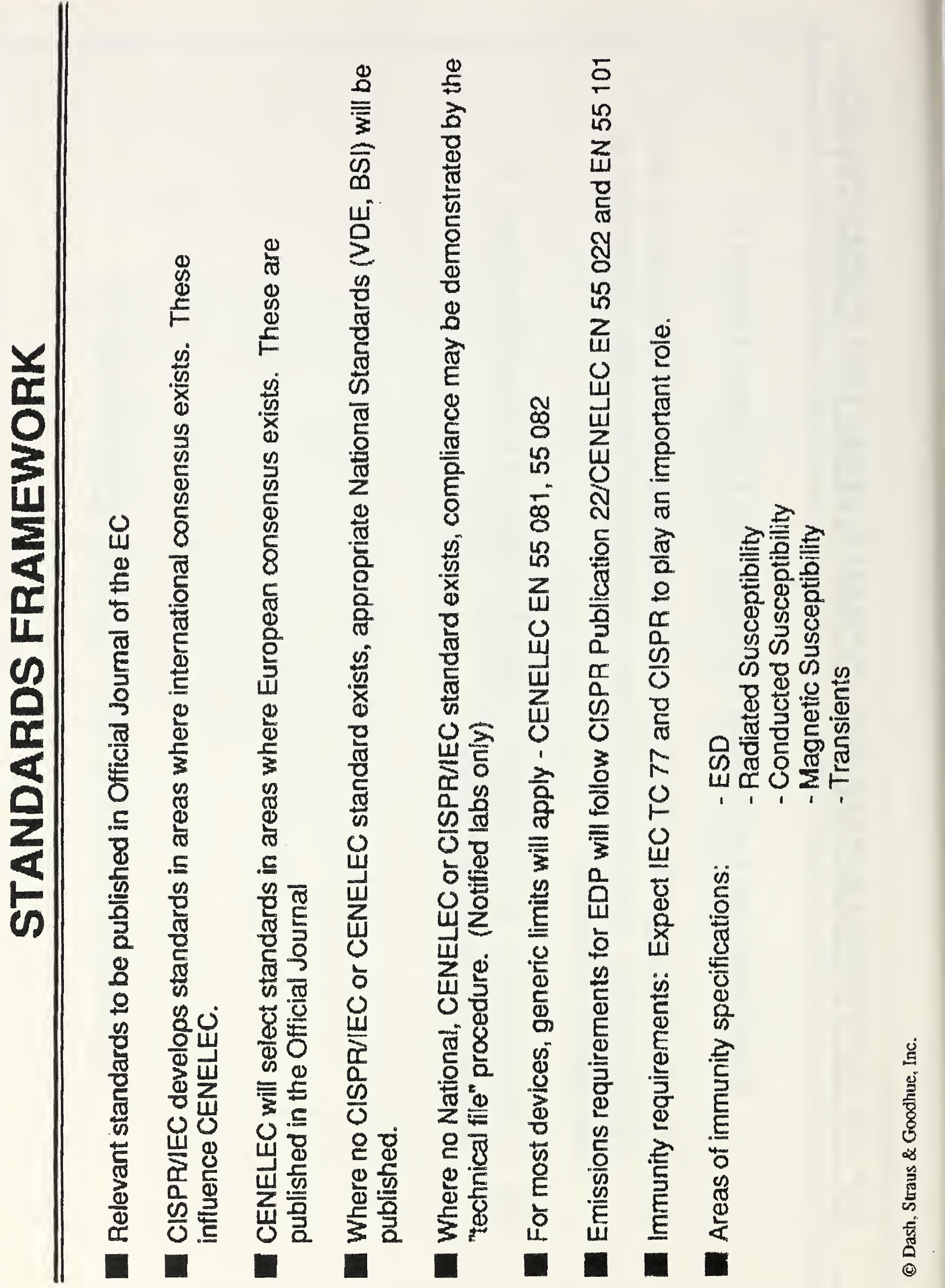


$\frac{0}{2}$ 


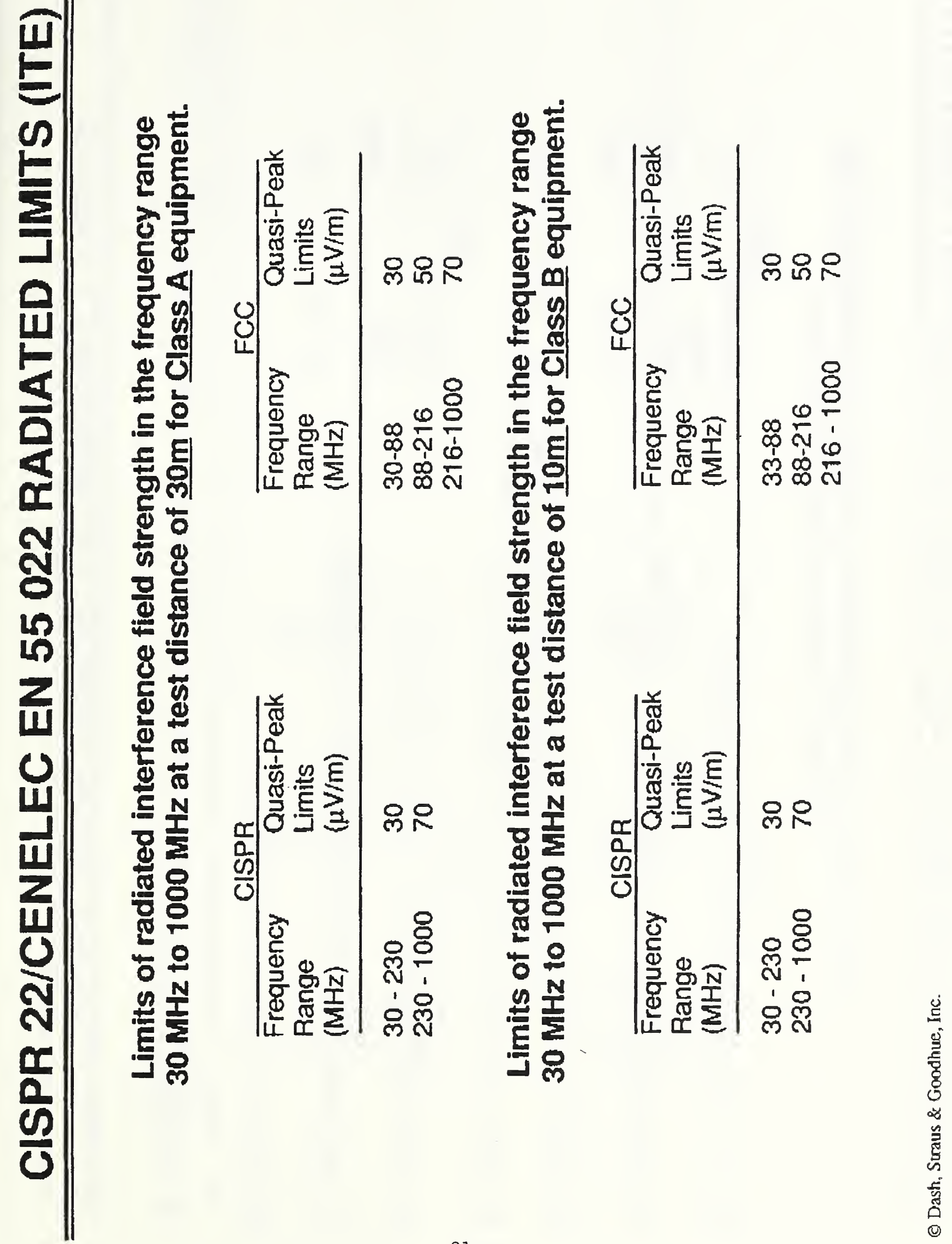




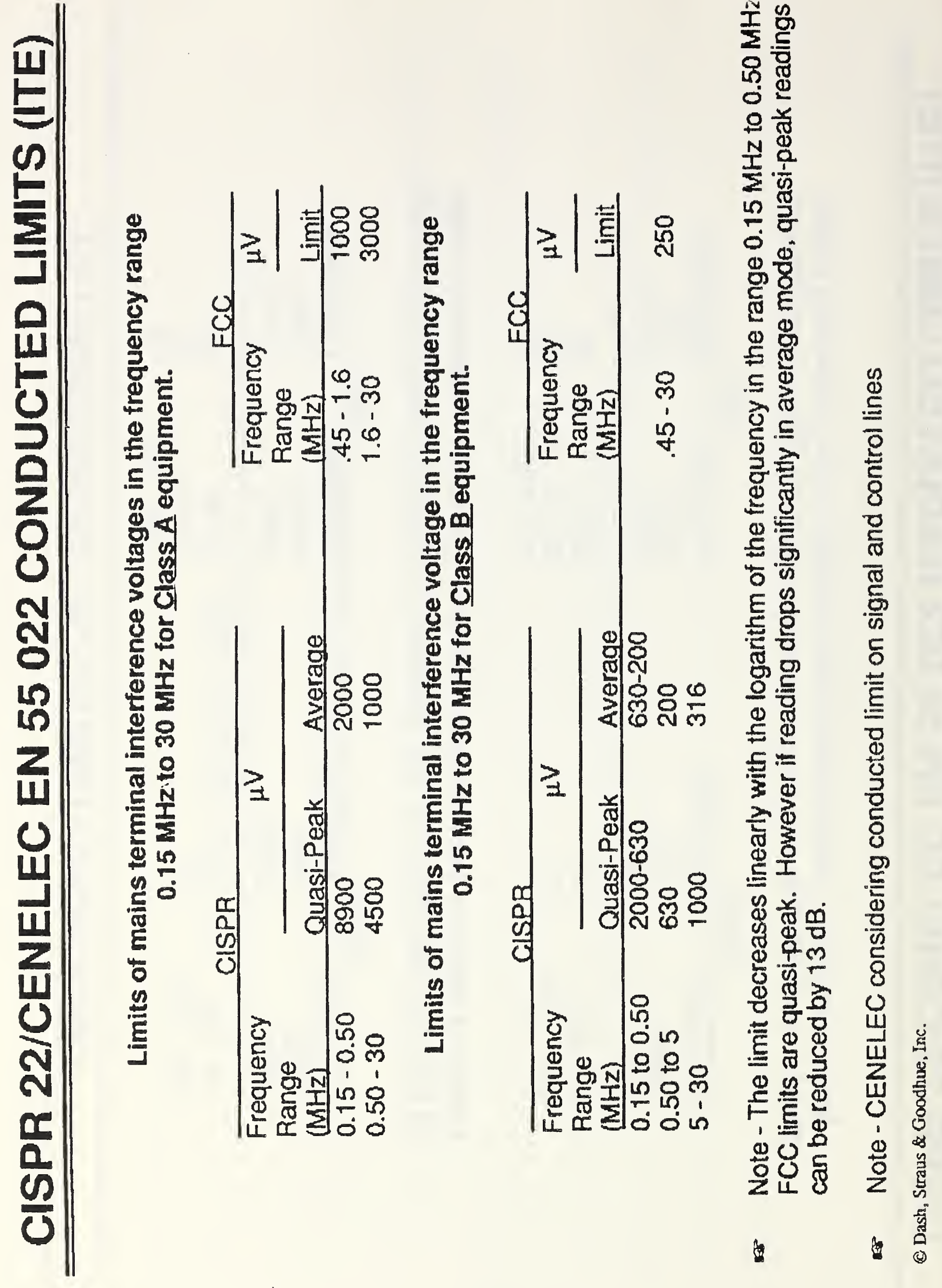




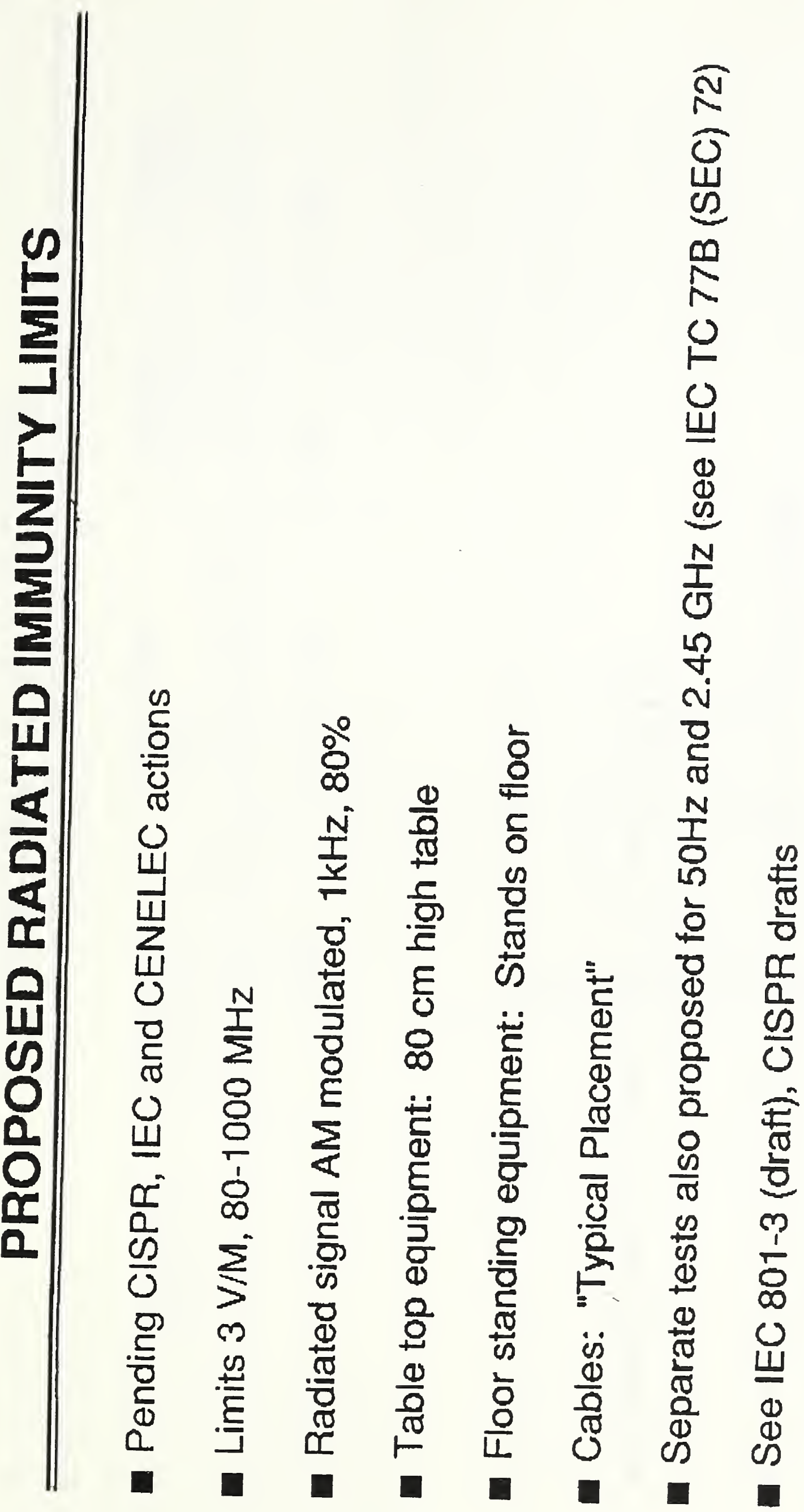


0

ज

$\stackrel{\infty}{1}$ 


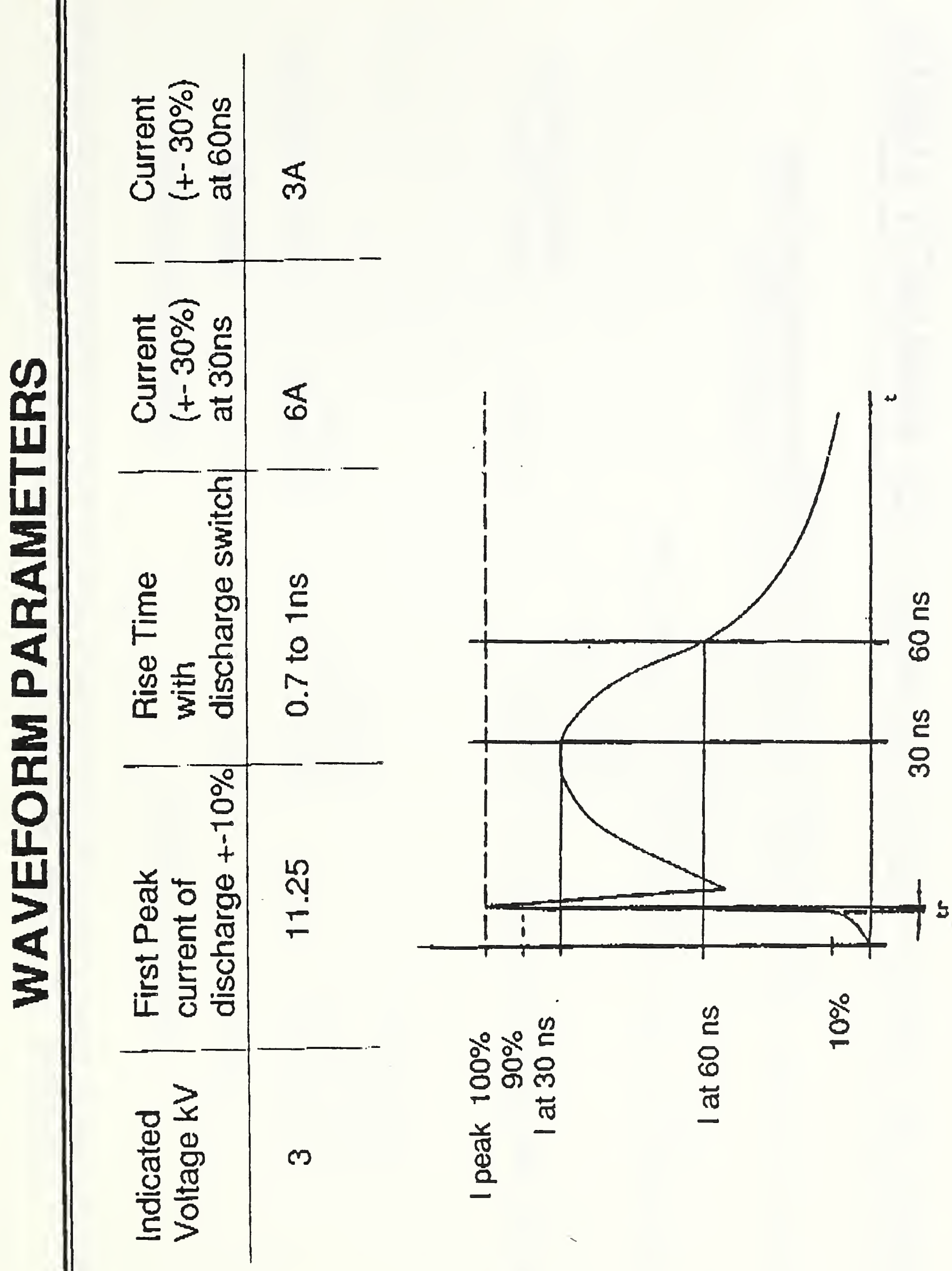




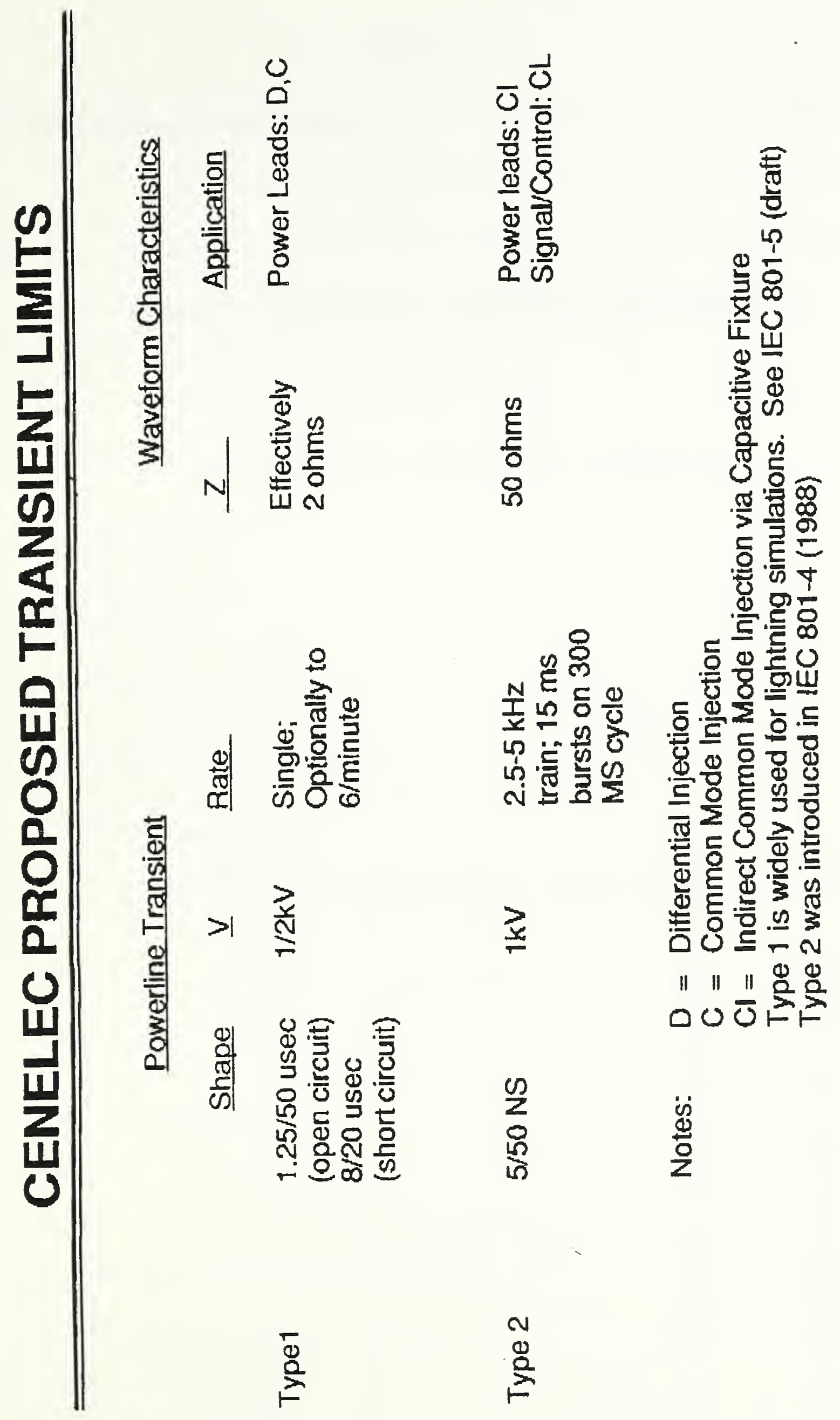




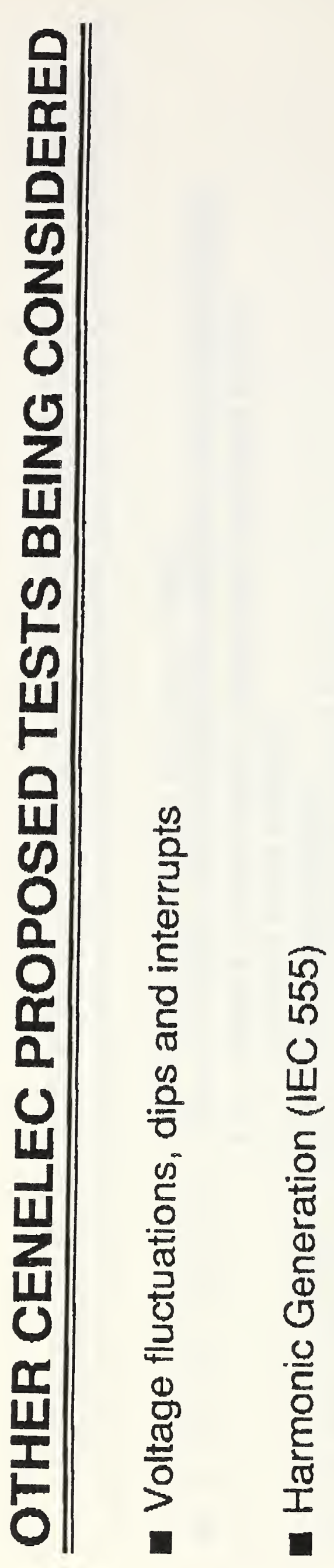




\section{Appendix D.4.}

(U) Underwriters Laboratories Inc.
Northbrook, Illinols • (708, 272-800u

Melville, New York • (516) 271-6200

Santa Clara, California • (408) 985-2400

Research Triangle Park,

North Carolina • (919) 549-1400

\title{
NATIONAL INSTITUTE OF STANDARDS AND TECHNOLOGY
}

\author{
ELECTROMAGNETIC COMPATIBILITY WORKSHOP
}

STATEMENT OF UNDERWRITERS LABORATORIES INC.

BY

KEITH MOWRY

APRIL 4, 1991 
THE NATURE OF THE EUROPEAN COMMUNITY'S STANDARDS AND PRODUCT APPROVAL PROCESSES HAVE BEEN THOROUGHLY COVERED BY THE DISTINGUISHED SPEAKERS FROM THE DEPARTMENT OF COMMERCE AND THE OFFICE OF THE UNITED STATES TRADE REPRESENTATIVE. I WILL NOT MUDDY THEIR VERY CLEAR PRESENTATION BY ADDING ANY COMMENTS IN THIS AREA.

HOWEVER, I WOULD OFFER SOME THOUGHTS ON TODAY'S WORKSHOP TO SUGGEST A CONTEXT FOR THE DISCUSSIONS. GENERALLY, DISCUSSIONS REGARDING PRODUCTS TRADED BETWEEN THE EMERGING EC SINGLE MARKET AND THE UNITED STATES CAN BE CHARACTERIZED INTO THREE GENERAL CATEGORIES:

DISCUSSIONS ABOUT PRODUCTS THAT ARE BOTH REGULATED IN THE EC AND THE US

DISCUSSIONS ABOUT PRODUCTS THAT ARE REGULATED IN THE EC BUT NOT REGULATED IN THE US 
DISCUSSIONS ABOUT PRODUCTS THAT ARE NOT NOW REGULATED

IN EITHER THE EC OR THE US

TODAY'S DISCUSSION REGARDING ELECTROMAGNETIC COMPATIBILITY

DEALS WITH MANY PRODUCTS THAT FALI INTO THE FIRST CATEGORY. THE EC, THROUGH ITS EMC DIRECTIVE, WILL BE REGULATING PRODUCTS. AS ALL HERE KNOW, THE FEDERAL COMMUNICATIONS COMMISSION REGULATES MANY OF THE SAME PRODUCTS IN THE US. AS A RESUIT WE ARE DEALING WITH PRODUCTS THAT, FOR THE MOST PART, ARE REgULATED IN THE EC AND IN THE US WITH RESPECT TO ELECTROMAGNETIC COMPATIBIIITY .

A POINT TO KEEP IN MIND TODAY, HOWEVER, IS THAT ELECTROMAGNETIC COMPATIBILITY IS BUT ONE ASPECT OF A PRODUCT THAT MAY BE IMPORTANT TO TRADE BETWEEN THE EC AND THE US. OTHER IMPORTANT CONCERNS IIKE CONSUMER HEALTH, IMPACT ON THE ENVIRONMENT AND ADDITIONAL PRODUCT SAFETY CONCERNS ARE 
ISSUES THAT THE EC MAY OR MAY NOT ADDRESS THROUGH

REGULATIONS. MORE IMPORTANT IS THE FACT THAT NOT ALL THESE PRODUCT CHARACTERISTICS ARE REGULATED IN BOTH THE US AND THE EC.

THIS CONSIDERATION IS IMPORTANT TO THE ORGANIZATION I REPRESENT, UNDERWRITERS LABORATORIES. AS MANY OF YOU KNOW UL OPERATES A COMPREHENSIVE SAFETY CERTIFICATION PROGRAM FOR A WIDE RANGE OF PRODUCTS. IN 1982, WE EXPANDED OUR PRODUCT SAFETY SERVICE TO INCLUDE ELECTROMAGNETIC INTERFERENCE TESTING SERVICES. THE GROWING USE OF RF SIGNALS TO CONTROL AND OPERATE DEVICES PRESENT, AND WILL CONTINUE TO PRESENT NEW CHALLENGES TO PRODUCT SAFETY EVALUATIONS.

THE DISTINCTION I WOULD LIKE TO MAKE IS THAT US PRIVATE SECTOR SAFETY CERTIFICATION EVALUATIONS INVOLVE SAFETY CONCERNS THAT ARE REGULATED IN THE EC BUT NOT SPECIFICALLY REGULATED IN THE US. AS A RESULT, THIS SAFETY CERTIFICATION 
ACTIVITY WOULD FALI IN TO THE SECOND TYPE OF DISCUSSION I MENTIONED EARLIER - PRODUCT CHARACTERISTICS REGULATED IN THE EC BUT NOT DIRECTLY REGULATED IN THE US. THIS SITUATION IS VERY DIFFERENT FROM THAT OF ELECTROMAGNETIC COMPATIBILITY WHICH BOTH THE EC AND THE US REGULATE. AS A RESULT, A COMPLETELY DIFFERENT SET OF PARAMETERS APPLY TO DISCUSSIONS ABOUT PRIVATE SECTOR SAFETY CERTIFICATION PROGRAMS AND US/EC TRADE AS COMPARED TO EMI TESTING PROGRAMS AND US/EC TRADE. AS I PARTICIPATE IN THE DISCUSSIONS TODAY, I WILL DO MY VERY BEST TO INDICATE TO WHICH AREA MY COMMENTS APPLY: REGULATED EMC TESTING OR UNREGUIATED PRODUCT SAFETY CERTIFICATION. TO CONCLUDE MY OPENING REMARKS I OFFER SOME BRIEF THOUGHTS ON THE QUESTIONS POSED IN THE FEDERAL REGISTER NOTICE ANNOUNCING THIS WORKSHOP. I BELIEVE ALL THE QUESTIONS SHOULD BE ANSWERED IN THE DUAL CONTEXTS OF THE NEEDS OF MANUFACTURERS WHO SEEK TO EXPORT THEIR PRODUCTS TO EUROPE AND DOMESTIC REGULATORY AND SAFETY NEEDS. 
WITH REGARD TO THE QUESTIONS POSED IN THE FEDERAL REGISTER I HAVE THE FOLLOWING COMMENTS REGARDING EMC ASPECTS OF PRODUCTS :

1 - WHICH EC REQUIREMENTS FOR CONFORMITY ASSESSMENT ARE APPLICABLE TO YOUR SECTOR? - THE EC IS FORMULATING AN EMC DIRECTIVE THAT WILL CUT ACROSS A BROAD RANGE OF PRODUCTS WITH FAIRLY GENERAL REQUIREMENTS. IN ADDITION, PRODUCT SPECIFIC DIRECTIVES (SUCH AS THOSE APPLYING TO MEDICAL DEVICES) MAY ALSO CONTAIN EMC REQUIREMENTS. THE GENERAL EMC DIRECTIVE IS SCHEDULED TO BE IMPLEMENTED PRIOR TO THE MEDICAL DEVICE DIRECTIVES. THE EC COMMISSION HAS PROVIDED VERBAL ASSURANCE THAT THE GENERAL EMC REQUIREMENTS AND THE PRODUCT SPECIFIC EMC REQUIREMENTS WILI BE COMPATIBLE. 
2 - DO EUROPEAN OR INTERNATIONAL STANDARDS THAT APPLY DIFFER FROM US STANDARDS? - I UNDERSTAND THAT THE FCC PUBLISHES SUGGESTED TESTING GUIDES FOR EMC AS WELL AS THE REGULATORY PERFORMANCE REQUIREMENT. ONE OF THESE GUIDES, MP-4, IS IN THE PROCESS OF BEING REPLACED WITH A PRIVATE SECTOR STANDARD, ANSI C63.4. AN EFFORT HAS BEEN MADE TO MAKE C63.4 CONSISTENT WITH INTERNATIONAL STANDARDS. I HAVE NO ADDITIONAL KNOWLEDGE REGARDING THE COMPATIBILITY BETWEEN THE REMAINING FCC TESTING GUIDES AND EUROPEAN OR INTERNATIONAL STANDARDS

$3 \& 4$ - THESE QUESTIONS DEAL WITH THE ADEQUACY OF US TESTING AND CERTIFICATION PROGRAMS TO MEET EXPORTERS' NEEDS AND THE DESIREABILITY OF MUTUAL RECOGNITION AGREEMENTS BETWEEN THE US AND EC GOVERNMENTS. THE VIEWS OF MANY DIFFERENT INTEREST GROUPS MUST BE CONSIDERED IN DEVELOPING ANSWERS TO THESE QUESTIONS. PERHAPS MOST IMPORTANTLY, THE NEEDS OF MANUFACTURERS EXPORTING TO 
EUROPE AND DOMESTIC REGULATORY AND SAFETY NEEDS MUST BE CONSIDERED. A MUTUAL RECOGNITION AGREEMENT BETWEEN GOVERNMENTS IS NOT THE ONLY OPTION AVAILABLE TO SATISFY THE NEEDS OF ALL CONCERNED. THE EC HAS INDICATED A WILLINGNESS TO ALLOW SUBCONTRACTING OF TESTING TO COMPETENT LABORATORIES OUTSIDE EUROPE. IN ADDITION, PRODUCT TESTERS AND CERTIFIERS CURRENTLY HAVE A MECHANISM IN PLACE TO BUILD CONFIDENCE IN ONE ANOTHER AND SHARE TEST DATA TO AN EXTENT THAT THE MUTUAL CONFIDENCE JUSTIFIES. THIS PROCESS, THE DATA PACKAGE EXCHANGE APPROACH, IS PRACTICED IN A VARIETY OF FORMATS AND PROCEDURES. IN FACT, MANY OF THE TEST LABS AT THIS TABLE PARTICIPATE IN THESE TYPES OF COOPERATIVE RELATIONSHIPS. QUESTIONS AND CONCERNS NO DOUBT EXIST REGARDING ALL OF THESE OPTIONS. WITH RESPECT TO MUTUAL RECOGNITION AGREEMENTS, A CONCERN OF COMPETENCE ARISES. THE EXISTANCE OF BILATERAL, CONFIDENCE BUILDING AGREEMENTS BETWEEN TESTERS THAT FORM THE BASIS OF THE 
DATA PACKAGE EXCHANGE APPROACH IS THE BEST EVIDENCE THAT TEST LABS THEMSELVES ACKNOWLEDGE DIFFERENCES IN COMPETENCE LEVEIS. WHAT OBLIGATIONS WOULD BE PUT ON THE US, AND PARTICULARLY THE FCC, REGARDING THE ACCEPTANCE OF TEST DATA FROM FOREIGN TEST LABS OF VARYING COMPETENCE LEVELS AS A RESULT OF A MUTUAL RECOGNITION AGREEMENT WITH THE EC? WOULD SUCH AN AGREEMENT REQUIRE THE FCC TO ACCPET DATA FROM ONLY EUROPEAN BASED NOTIFIED BODIES OR WOULD THE FCC BE REQUIRED TO ACCEPT TEST DATA FROM ALL NOTIFIED BODIES BOTH INSIDE AND OUTSIDE OF EUROPE? WOULD THE FCC BE PREVENTED FROM QUESTIONING A FOREIGN IAB'S CAPABIIITIES IF IT HAS PREVIOUSLY ACHIEVED NOTIFIED BODY STATUS? IS THE FCC READY TO HANDLE THESE POSSIBILITIES AND CONTINUE TO CARRY OUT ITS IMPORTANT REGULATORY SAFETY MISSION? THE ANSWERS TO THESE AND OTHER QUESTIONS MAY BE QUITE SIMPLE OR NOT SO SIMPLE. THE IMPORTANT POINT IS THAT ALL QUESTIONS SHOULD BE RAISED AND ADDRESSED. WITH THE 
EXISTING CHOICE OF OPTIONS, INCLUDING PERHAPS OPTIONS NOT YET IDENTIFIED, I AM CONFIDENT THAT ALI THE US NEEDS CAN BE MET.

5 - HOW CAN THE US GOVERNMENT BEST UTILIZE PRIVATE SECTOR INPUT WHEN DEVELOPING POSITIONS ON NEGOTIATING WITH THE EC? - THE GOVERNMENT MUST MAKE PRIVATE SECTOR INTERESTS AN INTEGRAL PART OF THE PROCESS THAT DEVELOPS THESE POSITIONS. BOTH MANUFACTURERS AND TESTING LABS SHOULD BE INCLUDED IN THIS PROCESS. PARTICIPATION BY THE FCC IN THESE ACTIVITIES IS ASSUMED. SINCE VARIOUS INDUSTRIES HAVE POTENTIALLY DIFFERENT NEEDS, WE SUGGEST A SECTOR BY SECTOR APPROACH BE CONSIDERED TO ADDRESS THESE ISSUES.

$6 \& 7$ - THESE QUESTIONS DEAL WITH THE USE OF A EUROPEAN PRODUCT MARK IN THE US AND THE DEVELOPMENT OF A US NATIONAL MARK - NEITHER OF THESE QUESTIONS SEEM TO BE 
GERMANE TO EMC. THE CURRENT FCC REQUIRED PHRASES ARE THE CURRENT US NATIONAL REQUIREMENTS FOR EMI INFORMATION OR PRODUCT MARKINGS ON CERTAIN PRODUCTS. PRODUCT MARKS, OR CERTIFICATION MARKS, PER SE ARE NOT NOW UTILIZED TO SHOW CONFORMANCE TO FCC REQUIREMENTS. THE MARKET, TO DATE, HAS NOT INDICATED A NEED FOR ADDITIONAL PRODUCT MARKS OR MARKINGS FOR EMI PURPOSES. UL WOULD NOT ADVOCATE THE INTRODUCTION OF A MARK IN AN AREA WHERE NO NEED FOR A MARK EXISTS. I WOULD EXPAND MY COMMENTS TO SAY THAT NO DEMONSTRATION OF NEED FOR A US NATIONAL MARK HAS EVER BEEN MADE FOR ANY PRODUCT OR INDUSTRY OF WHICH I AM AWARE

IN SUMMARY, SINCE EMC IS REGULATED IN BOTH THE EC AND THE US A WIDE VARIETY OF OPTIONS MAY EXIST TO ASSIST US EXPORTERS. BOTH THE TRADE NEGOTIATORS AND THE REGULATORS IN THE US GOVERNMENT WILL HAVE A MAJOR ROLE TO PLAY. THE GOVERNMENT SHOULD INTEGRATE THE PRIVATE SECTOR INTO THE PROCESS OF ANY 
NEGOTIATIONS WITH THE EC. FINALLY AND MOST IMPORTANTLY, DOMESTIC SAFETY CONSIDERATIONS AND THE NEEDS OF MANUFACTURING EXPORTERS MUST SIMULTANEOUSLY BE THE FIRST PRIORITY OF ALL INVOLVED.

THANK YOU VERY MUCH 
ELECTROMAGNETIC COMPATIBILITY WORKSHOP

NATIONAL INSTITUTE OF STANDARDS AND TECHNOLOGY

APRIL 4, 1991

CBEMA EMC CONCERNS

I. TIMELY DEVELOPMENT OF STANDARDS FOR EMISSIONS AND IMMUNITY:

Standards must be developed openly by committee consensus process, allowing time for comments, but not waiting until the last minute (December 31, 1991) to make decisions.

II. ADEQUATE PHASE-IN PERIOD FOR APPLYING THE STANDARDS:

The new standards may require test site changes as well as changes in measurement technique. A phase-in period of 18 months to 2 years would allow test site owner/operators to amortize costs and to train people in new techniques.

III. DEVELOPMENT OF STANDARDS FOR TESTING SITES:

Test site standards, open area, ground screen size, turntable, site attenuation bounds, actual measurement sequences, etc. per ANSI C63.4-1991 need to be developed.

IV. PROVISION FOR FULL RECOGNITION OF US EMC TEST HOUSES: A means of giving any recognized US test location equal status with any EC test location must be developed/negotiated.

V. EQUAL/FULL RECOGNITION OF MANUFACTURERS TEST SITES: An equipment manufacturers test site must be as fully recognized as an "independent" test site, i.e., 3rd party testing of telecom equipment should not be required.

VI. HARMONIZATION OF LIMITS AND TEST PROCEDURES:

FCC/CISPR/EN documents should be in harmony. For example, 3-step FCC limitations vs. 2-step CISPR/EN limits. FCC testing above $1 \mathrm{GHz}$, and CISPR/EN from $150 \mathrm{~K}-450 \mathrm{KHz}$ do not conflict, but are different. Test procedures are converging.

VII. ESTABLISHMENT OF FULL RECIPROCITY VS. E.C.:

U.S. must recognize VDE, TUV and other European standards, not just UL, if we expect the EC to give us full access and full recognition.

VIII. SET APPROPRIATE STANDARDS FOR DIFFERENT EQUIPMENT TYPES: $\mathrm{EC}$ is moving toward residential, light industrial and heavy industrial limits. FCC has exempted "heavy industrial" by its wording in "exemptions." We need consistency.

IX. ALLOW MANUFACTURERS DECLARATION OF CONFORMANCE TO STANDARDS: Relates to V. A manufacturers declaration of conformance to any set of standards should be "equally recognized" as well as an independent test house's test report on the same piece of equipment. 
Dr. Mirko Matejic

Codex-Motorola

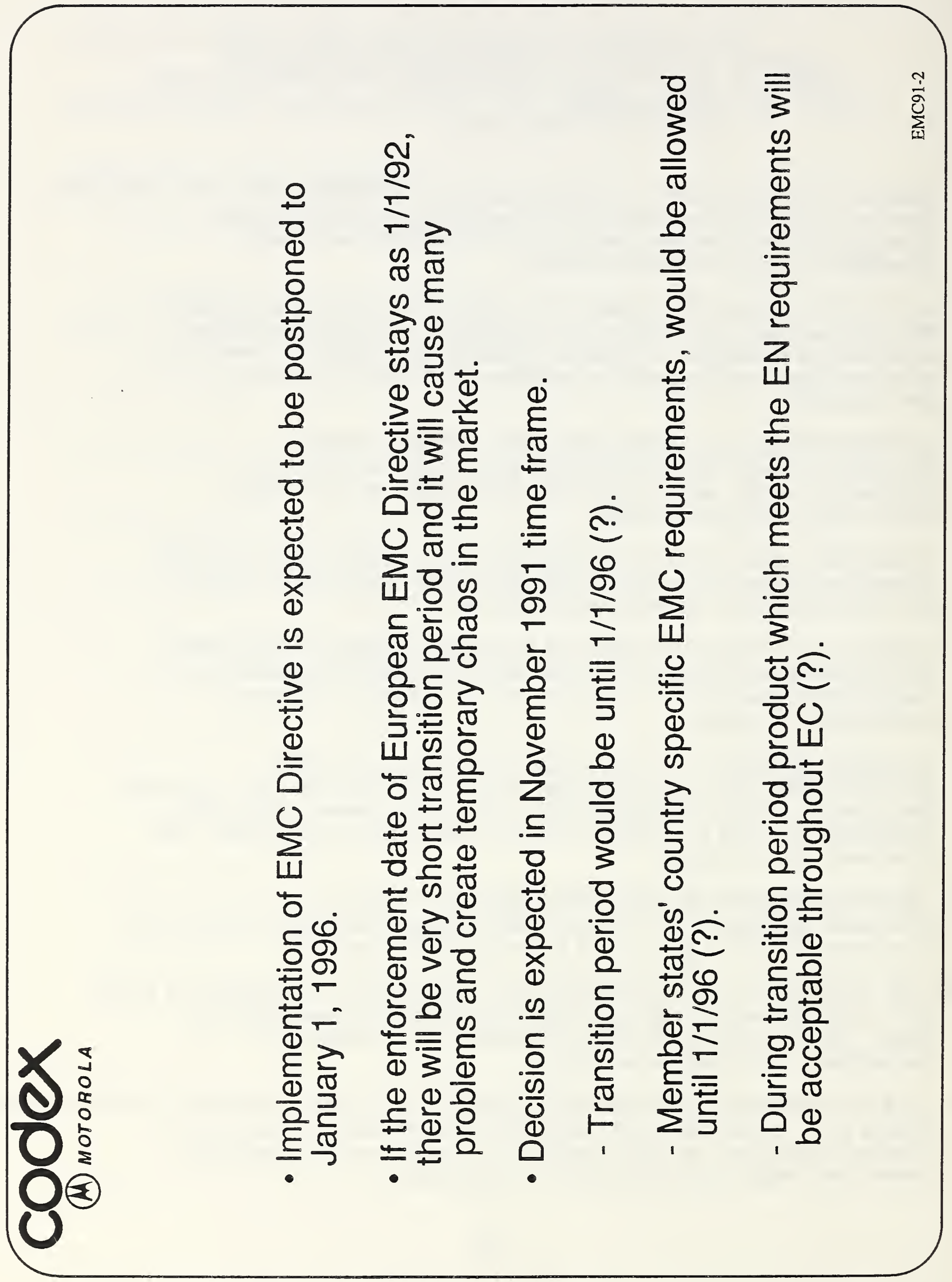




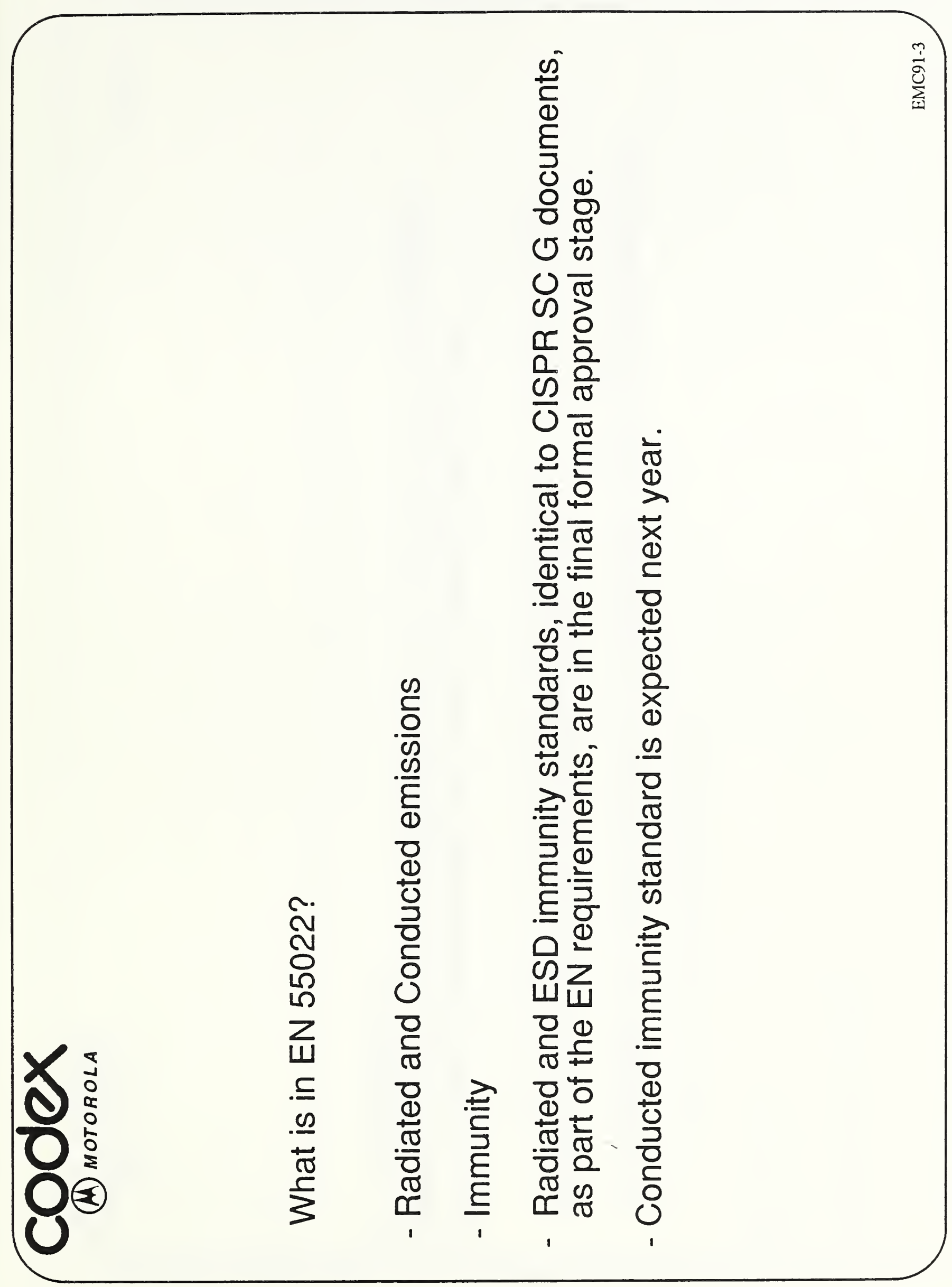




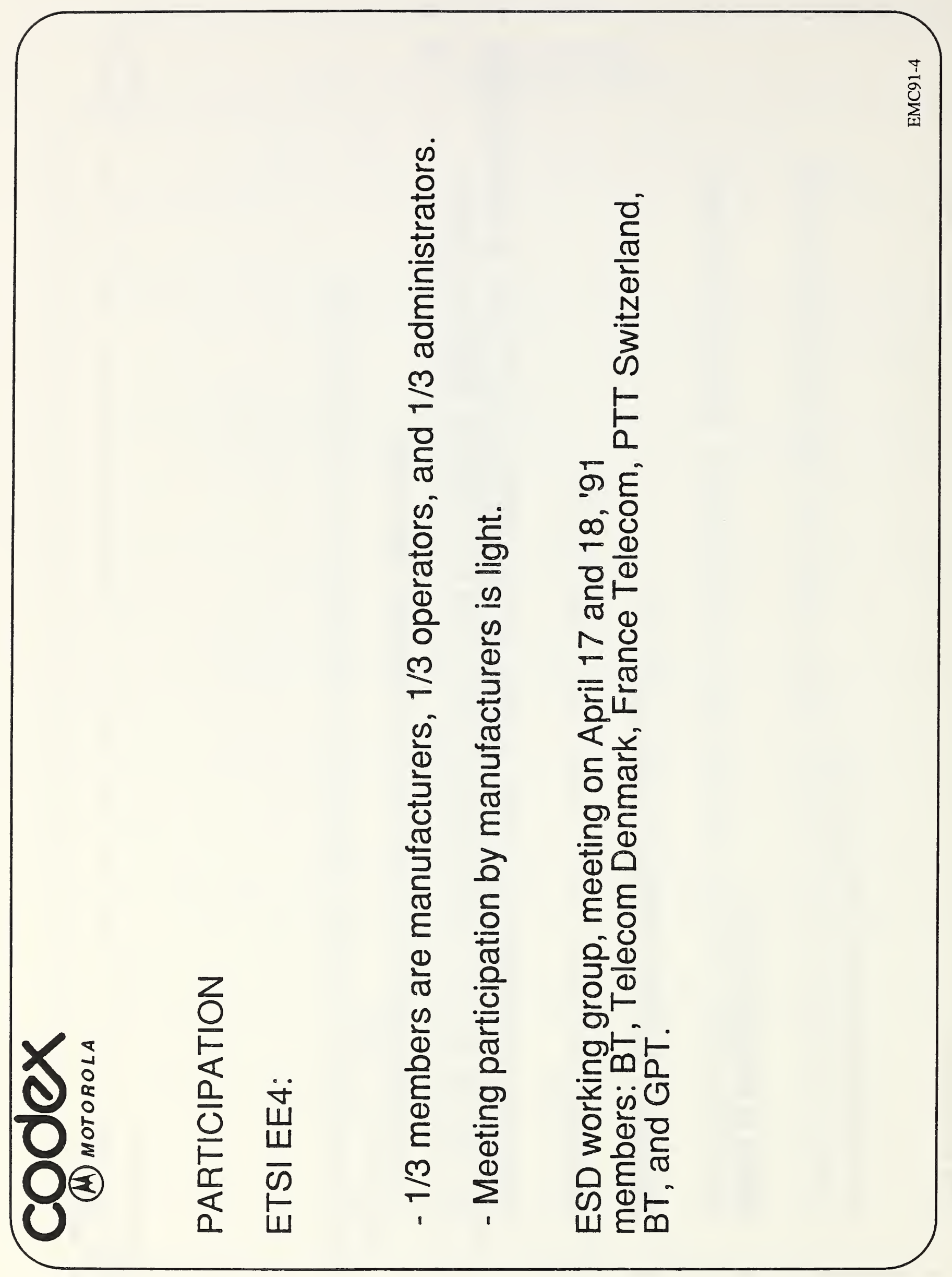




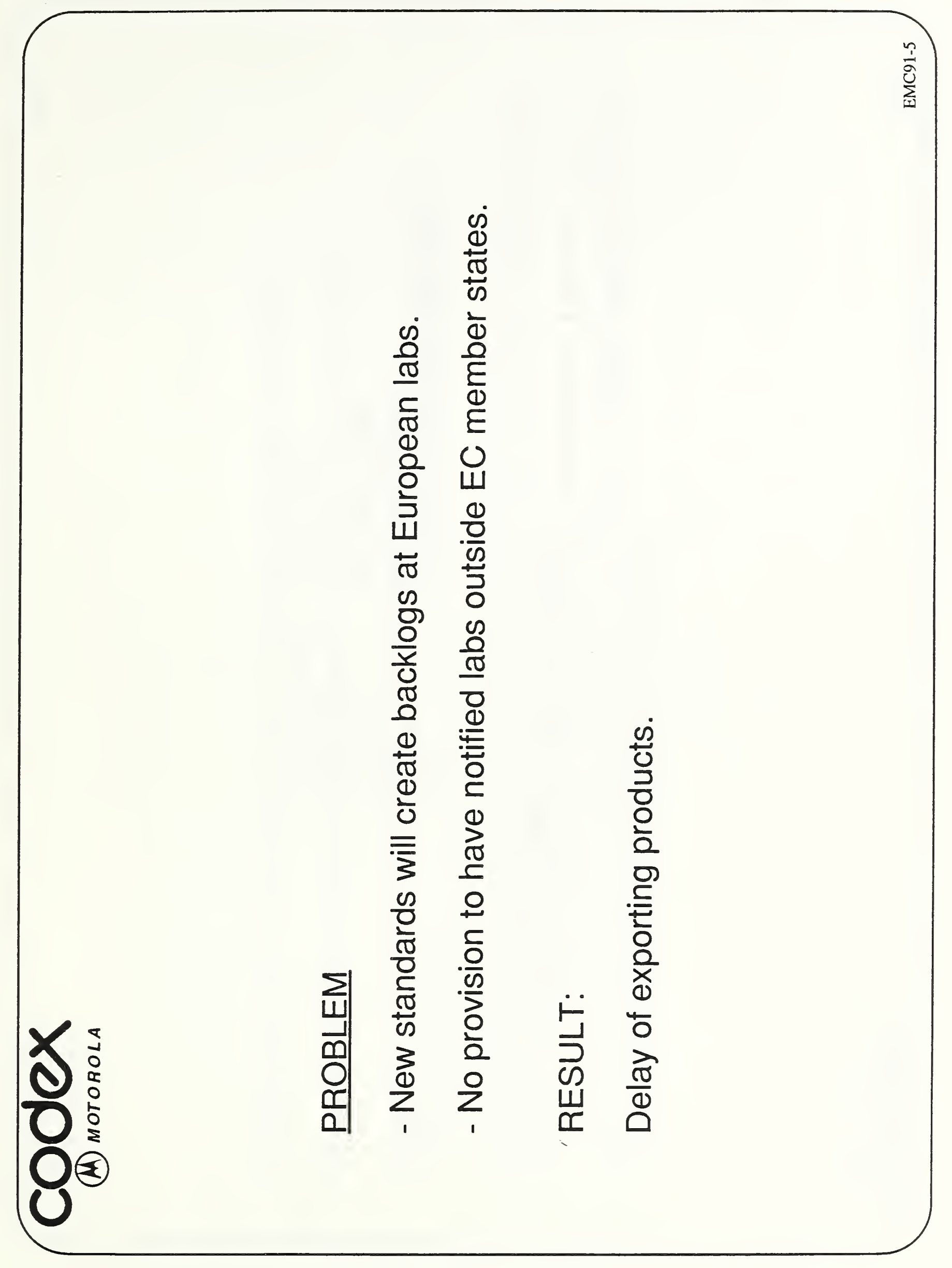




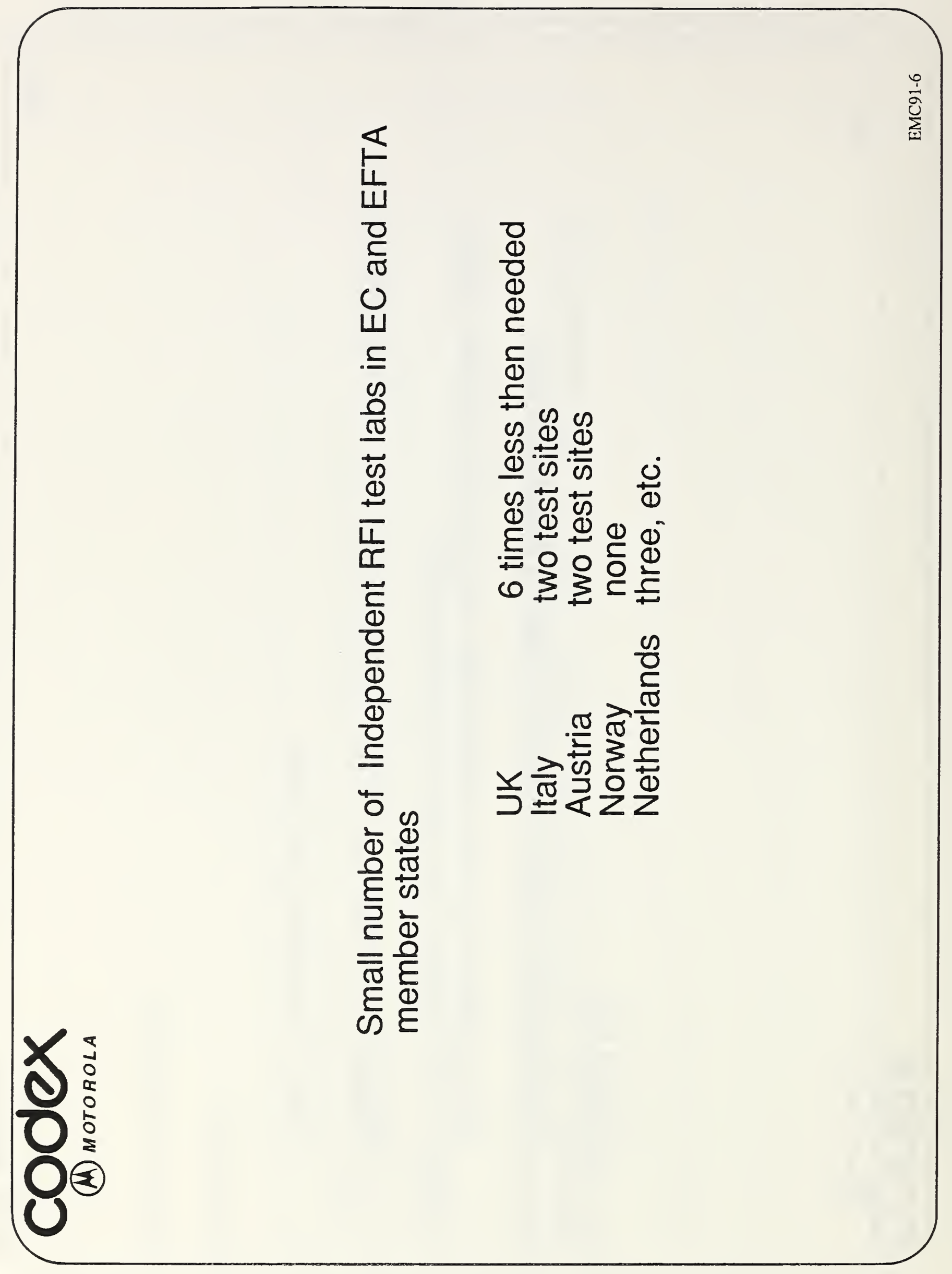




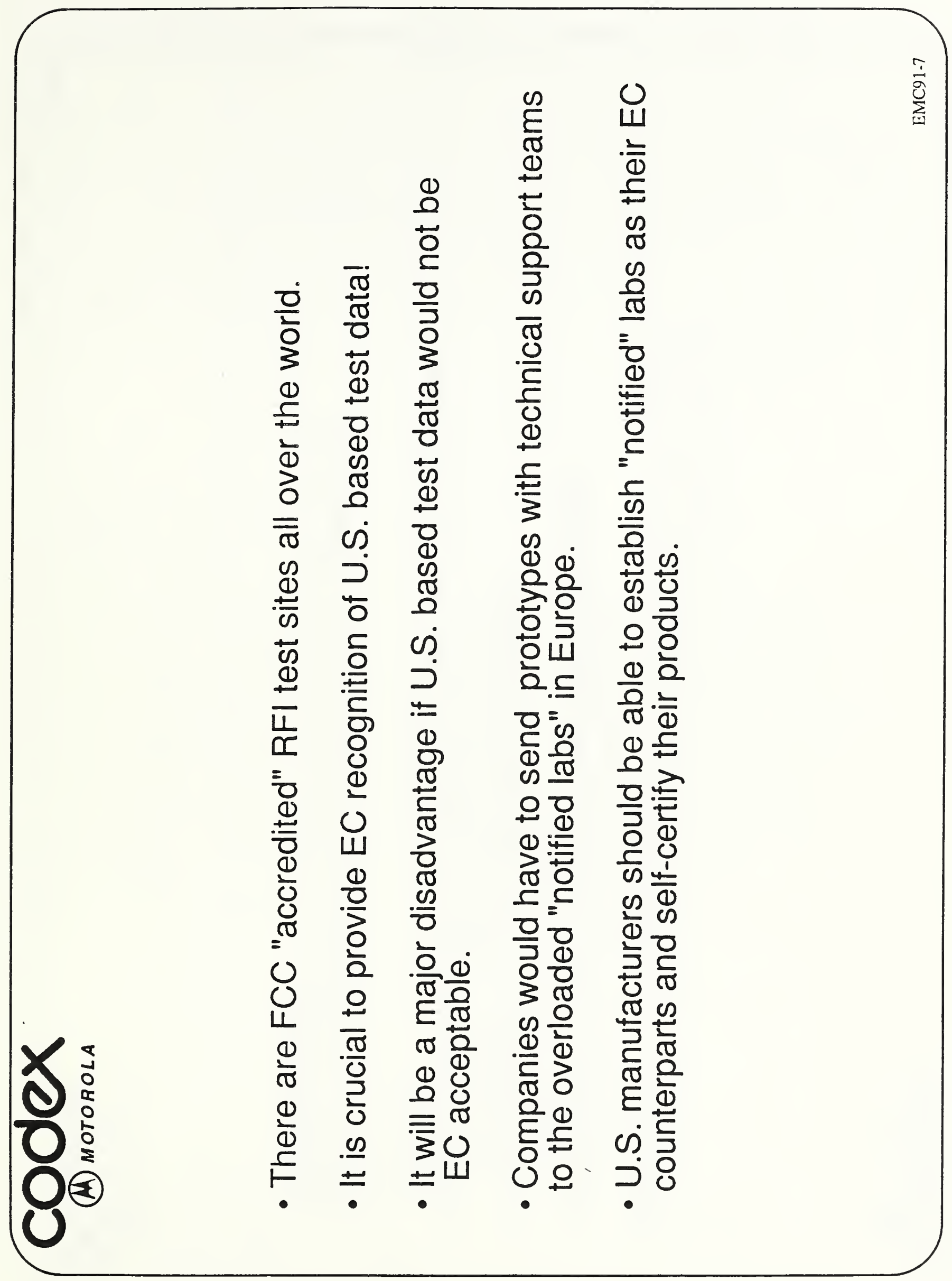




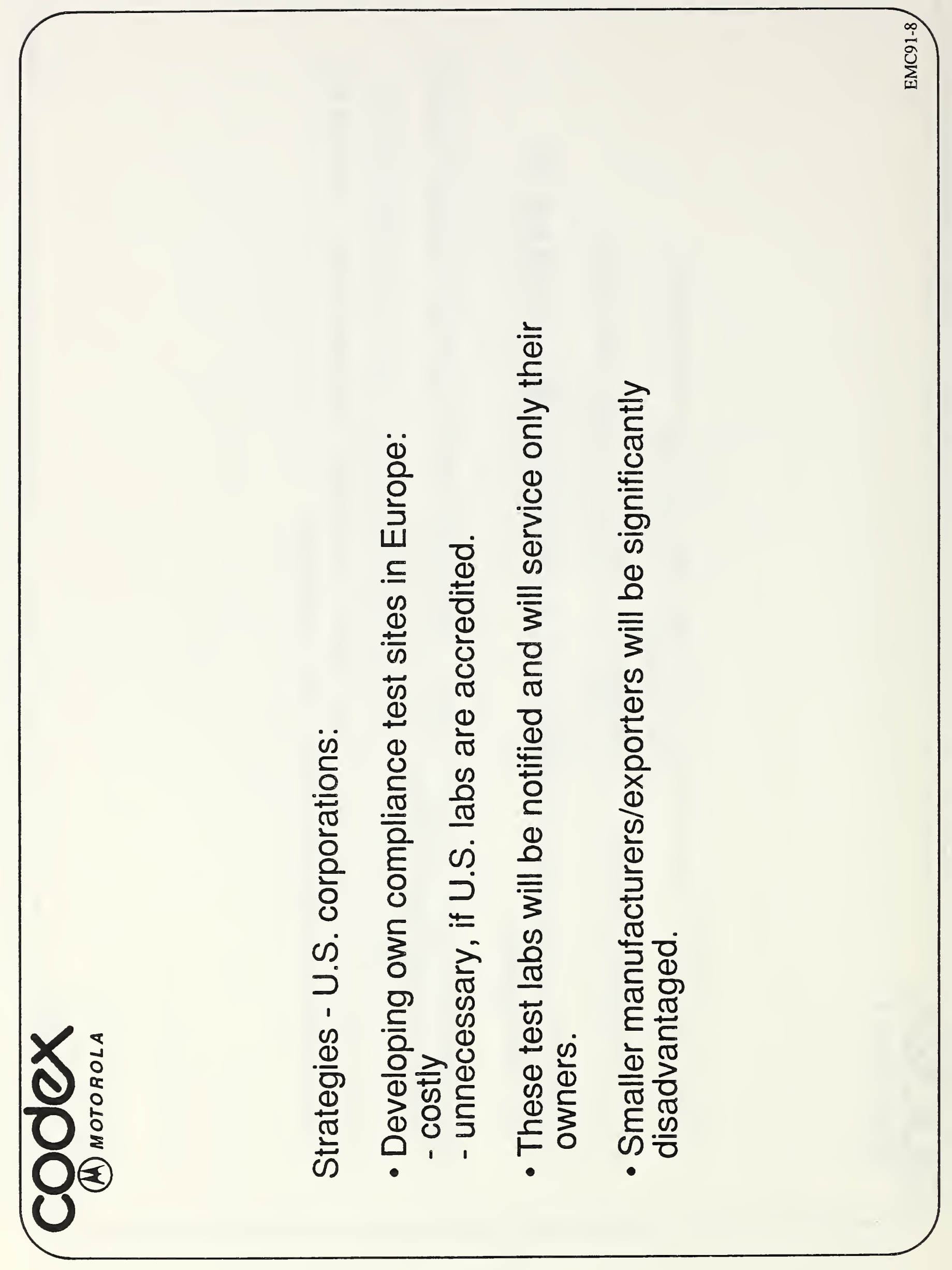




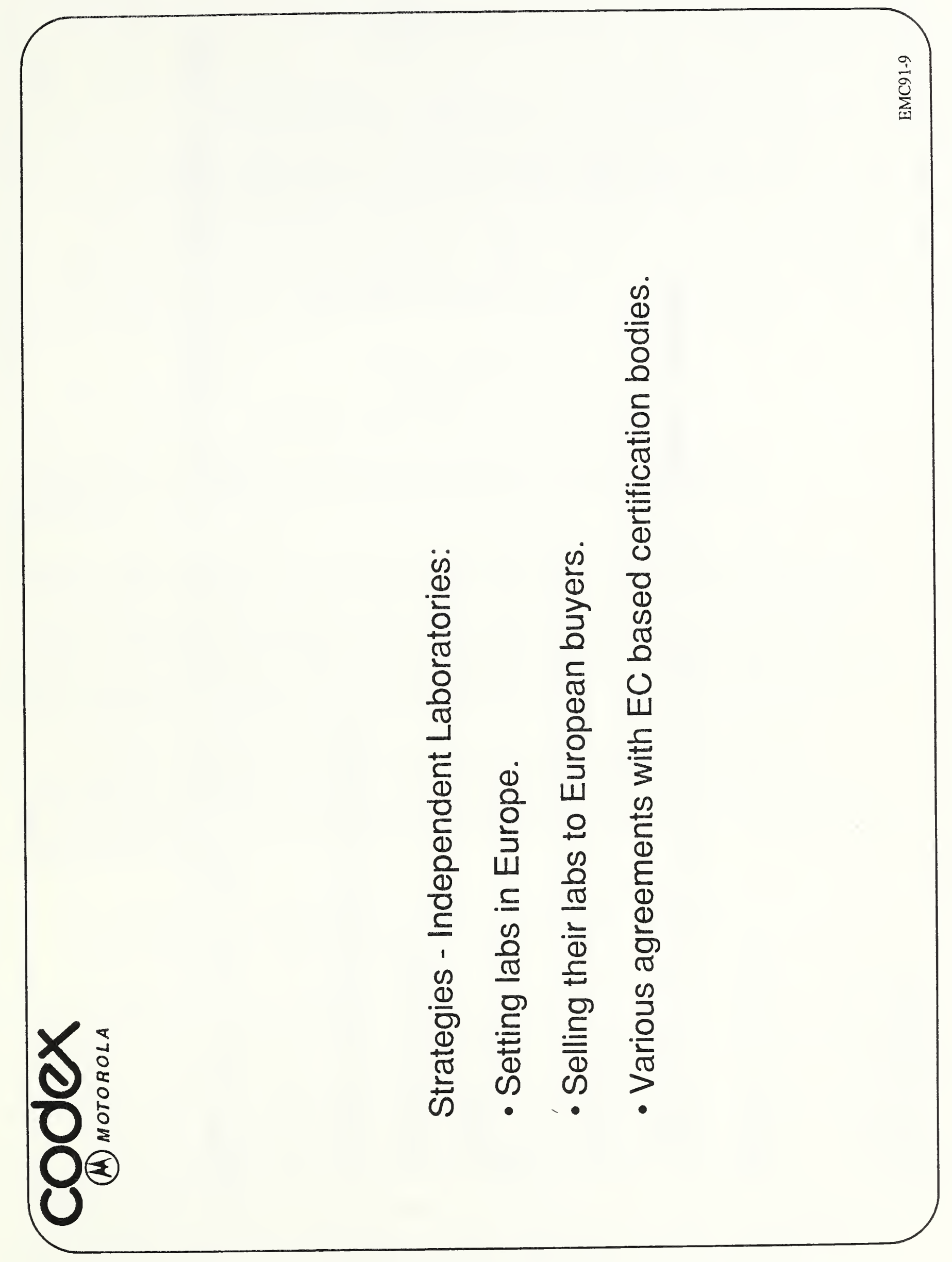




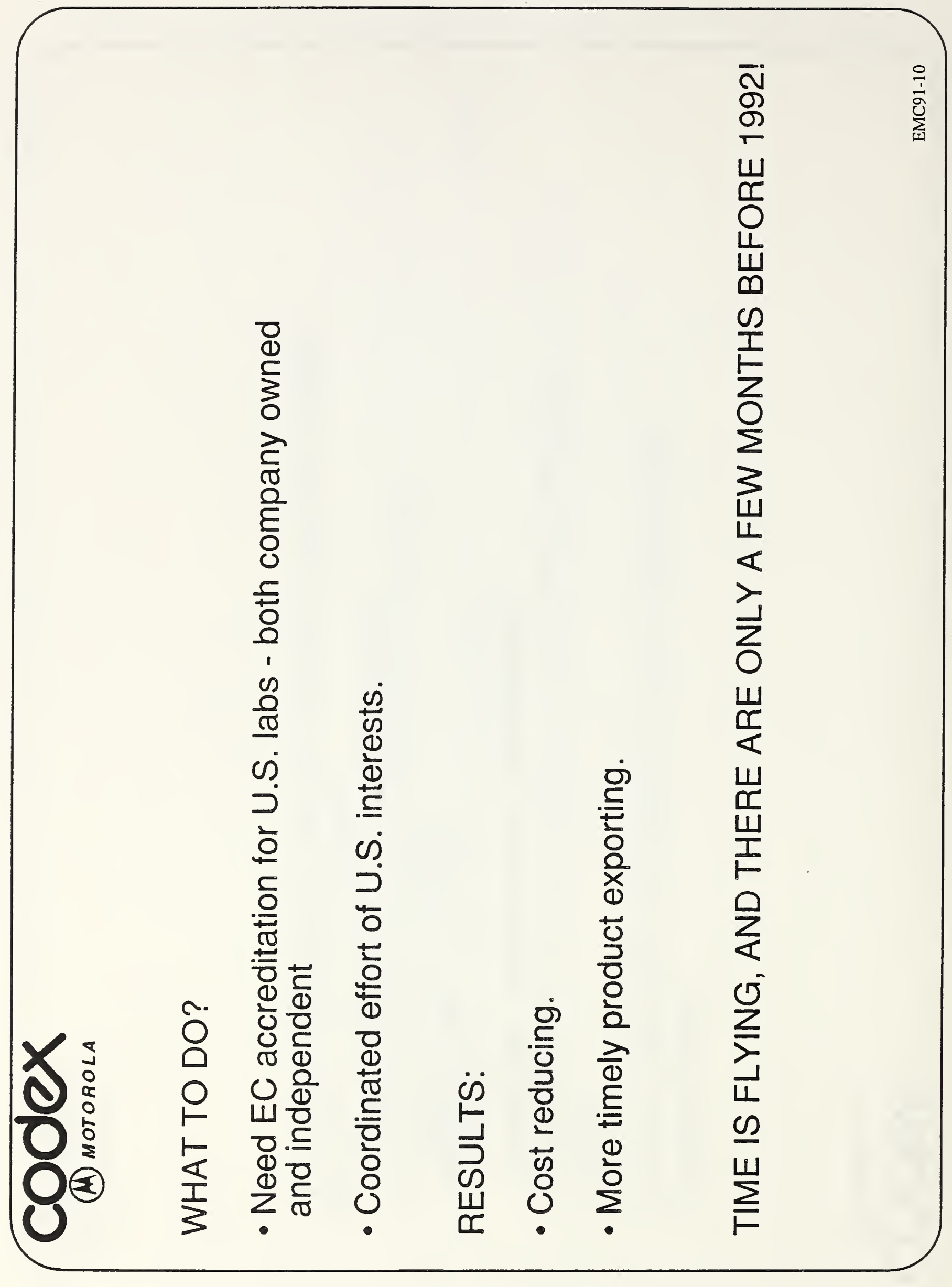


Appendix D.7.

\author{
ELECTROMAGNETIC COMPATIBILITY WORKSHOP \\ National Institute of standards \\ American Council of Independent Laboratories \\ american Electronics Association
}

April 4, 1991

STATEMENT SUBMITTED BY

\author{
PETER BOERS \\ title \\ Digital Equipment Corporation
}

(Peter Boers is a senior engineering manager with the Digital Equipment Corporation. His responsibilities include work in the EMC area.)

Digital Equipment Corporation appreciates the opportunity to participate in today's workshop and to offer these brief comments.

Digital Equipment Corporation is a leading U.S.-based, worldwide supplier of networked computer equipment. With some 50 percent of Digital's total worldwide revenue generated in the EC, the technical and regulatory issues discussed today are of obvious substantial interest to my company.

In my brief remarks. I want to ignore briefly technical and requlatory ccmplexity of the issue we are discussing today. Instead, at the risk of over-simplification, I am going to set out just two rather straightforward statements about the problem and its possible solution.

1. The proposed EC scheme raises no technical problems, but it will have a serious, negative impact on U.S. firms that do not have their own testing facilities in the EC.

One of the tentative topics listed for today's workshop asked whether European regional standards (CEN/CENELEC/ETSI) or internationai standards (ISO, IEC, CCITT) that apply to industry sectors differ from U.S. standards. The answer in the area of computers and information technology more broadly is clearly "yes." But that does not mean that Digital (and presumably the rest of U.S. industry able to meet U.S. standards! will have any technical difficulty meeting these European or international standards. In fact, from a technical standpoint, meeting these standards is really no problem at ali.

The problem posed by the EC's planned approach is that companies outside the EC will be slowed in their ability to introduce new products due to the need to bring prototypes and development engineers over from the U.S. to the EC for testing to duplicate the 
testing that will have already taken place closer to home. Either this diversion of prototypes and engineers will take place during (and thus extending) the development cycle, or it will occur after the cycle is completed in the U.S., thus delaying product

introduction. Either way, this delay will have substantialiy handicapped U.S. Firms' ability to succeed in the market yith latest, short-Iife-cycie high technology products.

Within the EC, the firns that will gain most from U.S. Firms' disadvantage are those large firms that have established theif own test facilities. For local firms, time to market will hardly be affected, if at all, by implementation of the EC testing procedure. EC firms without theif own testing laboratories will nonetheless be advantaged relative to U.S. firms, because the cost of making their European-based engineers and prototypes available for testing will be far less, both in money and time.

2. The problem requires a compromise solution, and the appropriate solution is for the EC to allow manufacturers declaration of conformity to standards.

Despite talk of possibie delayed implementation, it seens a certainty that the $E C^{\prime} s$ scheme will one day come into effect -maybe less than a year from today. Consequently, we should let go of a shared wish that the entire problem would disappear. one day, the scheme will be with us, and we need to do something to make certain that its impact is not as sketched out above.

The oniy two possible solutions that present themselves are:

1) manufacturers' self-certification; and

2) establishment of full reciprocity.

Digital and the rest of the U.S. computer industry strongly support the first of these approaches. As I implied earlier, testing and certifying to EMC compliance is not a matter of any substantia? technical complexity. Therefore, testing in this area lends itself quite easily to a self-test and certification procedure. Vaturally: details of how the self-certification system would work, and arrangements for establisining mutual recognition of such self-certifications, would need to be worked out.

A second-best approach wolid be to establish a system of fuil reciprocity between U.S. and EC testing laboratories. While in principle this would work well, it is not clear that there currentiy exist the mirror-image conditions that would create the possibility for implementing a system of full reciprocity.

In suggesting this solution path, I am echoing the position taken by U.S. industry from the first days this issue arose. Today. I worry that the U.S. and EC governments seem still to be talking past each other about the need For one or the other of these solutions. This problem is real, and it is essential that dancing stop and that serious negotiating begin. I hope I'm echoing the views of others in industry when I say that we stand ready to give our government technical and any other advice that would help the government achieve the solution that U.S. industry needs.

Thank you. 

